\title{
Impact of GODAE Products on Nested HYCOM Simulations of the West Florida Shelf
}

George R. Halliwell, Jr.

\author{
MPO/RSMAS, University of Miami, 4600 Rickenbacker Causeway, \\ Miami, FL
}

Phone: 1-305-421-4621; fax: 1-305-421-4696; ghalliwell@,rsmas.miami.edu

Alexander Barth

National Fund for Scientific Research, University of Liege, Belgium

Robert H. Weisberg

University of South Florida, St. Petersburg, FL

Patrick Hogan

Naval Research Laboratory, Stennis Space Center, MS

Ole Martin Smedstad

QinetiQ North America, Technology Solutions Group, PSI, Stennis Space Center, MS

James Cummings

Naval Research Laboratory, Monterey, CA

Abstract. Nested non-assimilative simulations of the West Florida Shelf for 20042005 are used to quantify the impact of initial and boundary conditions provided by GODAE ocean products. Simulations are nested within an optimum interpolation hindcast of the Atlantic Ocean, the initial test of the U. S. Navy Coupled Ocean Data Assimilation system for the Gulf of Mexico, and a global ocean hindcast that used the latter assimilation system. These simulations are compared to one that is nested in a non-assimilative Gulf of Mexico model to document the importance of assimilation in the outer model. Simulations are evaluated by comparing model results to moored Acoustic Doppler Current Profiler measurements and moored sea surface temperature time series. The choice of outer model has little influence on simulated velocity fluctuations over the inner and middle shelf where fluctuations are dominated by the deterministic wind-driven response. Improvement is documented in the representation of alongshore flow variability over the outer shelf, driven in part by the intrusion of the Loop Current and associated cyclones at the shelf edge near the Dry Tortugas. This improvement was realized in the simulation nested in the global ocean hindcast, the only outer model choice that contained a realistic representation of Loop Current transport associated with basin-scale wind-driven gyre circulation and the Atlantic Meridional Overturning Circulation. For temperature, the nonassimilative outer model had a cold bias in the upper ocean that was substantially corrected in the data-assimilative outer models, leading to improved temperature representation in the simulations nested in the assimilative outer models.

Numerical modeling, coastal circulation 


\section{Introduction}

At the open boundaries of coastal ocean models, it is necessary to prescribe an accurate representation of momentum and water properties along with their crossboundary fluxes. This is required to properly represent the influence of offshore processes such as boundary current and eddy variability on coastal ocean circulation. Regional to global ocean hindcasts generated as part of the Global Ocean Data Assimilation Experiment (GODAE) are an attractive choice for providing this offshore forcing. Nesting coastal models is desirable because GODAE products are suboptimal for studying the coastal ocean due to factors such as insufficient horizontal, vertical, and temporal resolution in model output, the use of low-resolution atmospheric forcing, inadequate representation of river/estuarine runoff, and the absence of tidal forcing. Since GODAE products are now in various stages of development and evaluation, their strengths and weaknesses for providing initial fields and offshore boundary forcing to nested coastal models remain to be evaluated.

In addition to energetic forcing by the atmosphere and coastal river/estuarine runoff, the West Florida Shelf (WFS, Figure 1) is influenced by energetic offshore variability associated with the Loop Current (LC) and adjacent rings and eddies. These offshore features influence property exchanges across the shelfbreak, and the LC can, under certain conditions, exert a strong influence on the flow and thermodynamical structure over the shelf (Paluszkiewicz et al., 1983; He and Weisberg, 2003; Weisberg and He, 2003). Because of the Taylor-Proudman constraint stating that low Rossby number currents will flow parallel to local isobaths if friction and time dependence are negligible, the direct dynamical influence of offshore eddy forcing over a continental shelf much wider than the local Rossby radius of deformation will remain confined to the outer shelf (e.g. Chapman and Brink, 1987; Kelly and Chapman, 1988). This scenario is true along most of the WFS except at the northern end near the DeSoto Canyon, and at the southwestern end near the Dry Tortugas (Figure 1). The narrow shelf near DeSoto Canyon permits eddy fluctuations to strongly impact shelf circulation and produce large cross-shelf exchanges (Huh et al., 1981; Weisberg et al., 2004; Weisberg et al., 2005). The LC influences outer shelf flow along the entire WFS when its path is situated adjacent to the shelfbreak near the Dry Tortugas (e.g. Hetland et al, 
1999). Pressure perturbations over the shelf induced by LC flow in this region propagate northward and the resulting geostrophic adjustment produces southward flow over the entire shelf (Weisberg and He, 2003). In contrast, a LC intrusion event along the broad central WFS was confined to the outer shelf due to the Taylor-Proudman constraint (He and Weisberg, 2003). When the TaylorProudman constraint is broken, either by pressure perturbation adjustment across shallow isobaths or directly by bottom friction, a significant cross-shelf transport of offshore water may occur within the bottom boundary layer (He and Weisberg, 2003; Weisberg and He, 2003; Weisberg et al., 2004).

This offshore influence coexists with large variability driven by synoptic atmospheric systems, particularly tropical waves and cyclones in summer/fall, and cold front passages during the remainder of the year (Niiler, 1976; Mitchum and Sturges, 1982; Cragg et al., 1983; Marmorino, 1983; Mitchum and Clarke, 1986a; 1986b; Weisberg et al., 2001). The inner shelf responds to wind through a classical Ekman-geostrophic spinup (Weisberg et al., 2000) while stratification is very influential in that it: (1) sets the vertical distribution of mixing and hence the Ekman layer interactions and (2) produces an upwelling and downwelling response asymmetry by thermal wind effects on the bottom Ekman layer (Weisberg et al., 2001). As a result, wind-driven downwelling currents tend to be confined closer to the coast than upwelling currents (Liu and Weisberg, 2005; 2007). This atmospherically forced response is not totally independent of the response to offshore forcing. Large time dependent variability between upwellingand downwelling-favorable winds along with large friction present in both the surface and bottom boundary layers can break the Taylor-Proudman constraint and permit large cross-shelf transport of water properties (Weisberg et al., 2005).

The two scientific goals of this paper are to (1) evaluate the impact of GODAE ocean hindcasts on simulations of the West Florida Shelf (WFS) and (2) evaluate a regional implementation of the HYbrid Coordinate Ocean Model (HYCOM) as part of a larger effort to develop an ocean model with a sufficiently flexible vertical coordinate to quasi-optimally represent the transition between the deep and coastal ocean. The first goal addresses the central theme of this special issue, and also addresses a specific GODAE objective: apply state-of-the-art models and 
assimilation methods to produce boundary conditions that extend predictability of coastal and regional subsystems (International GODAE Steering Team, 2000).

To address these goals, three GODAE data-assimilative ocean hindcasts are evaluated for providing offshore forcing to nested WFS simulations. These hindcasts all use the HYbrid Coordinate Ocean Model (HYCOM) and represent different stages of the ongoing development of the next-generation U. S. Navy ocean nowcast-forecast system. Due to ongoing improvements in model physics and parameterizations, resolution, bathymetry, and assimilation techniques, significant differences exist in the representation of the offshore ocean among these HYCOM-based products. This fact enables meaningful sensitivity studies to be conducted by nesting non-assimilative WFS simulations within them. The impact of nesting within data-assimilative outer models is also contrasted against nesting within a non-assimilative ocean model. This comparison is designed to identify improvements in the nested coastal simulation that are achieved when the outer model more realistically represents offshore currents and eddies. Barth et al. (2008) nested WFS simulations performed with the Regional Ocean Modeling System (ROMS) in climatology and in a HYCOM-based data-assimilative ocean hindcast and documented improvements in the flow field produced by the model nested in the ocean hindcast.

This paper is organized as follows: The ocean model is described in Section 2, the GODAE ocean products used to provide initial and boundary conditions are described in Section 3, and the moored observations against which the nested ocean simulations are evaluated are described in Section 4. The setup of the nested WFS simulations along with evaluation procedures are outlined in Section 5. Section 6 documents the sensitivity of simulated velocity fluctuations over the WFS to the different outer model products while Section 7 documents the sensitivity of simulated surface temperature fluctuations. Conclusions are presented in Section 8. The study of Kourafalou et al (2008, this issue) complements the present analysis by focusing on the impact of GODAE products in the South Florida coastal region, including the Florida Straits. 


\section{Model Description}

The HYbrid Coordinate Ocean Model (HYCOM; http://www.hycom.org) is designed to use Lagrangian isopycnic coordinates throughout as much of the stratified ocean interior as possible, but perform a dynamical transition to fixed vertical coordinates, either level $(p)$ or terrain-following $(\sigma)$, in regions where isopycnic coordinates are sub-optimum. Fundamental properties of the model are presented in Bleck (2002), Chassignet et al. (2003), and Halliwell (2004). Since basic features of the model are also summarized in Kourafalou et al. (2008, this issue), the present discussion is limited to model features central to this study.

HYCOM evolved from the Miami Isopycnic-Coordinate Model (MICOM; Bleck et al., 1992; Bleck, 1998), Although fixed coordinates are maintained in some regions, the model remains a purely Lagrangian layer model, and the procedures used to solve MICOM equations are unmodified except for executing the hybrid "grid generator" at the end of each baroclinic time step to relocate layer interfaces (Bleck, 2002). HYCOM therefore remains a Lagrangian Vertical Dynamics (LVD) model where the continuity (thickness tendency) equation is solved prognostically throughout the domain. Fixed $p$ or $\sigma$ coordinates are maintained by the grid generator, which is essentially an Arbitrary Lagrangian-Eulerian (ALE) technique (e.g. Adcroft and Hallberg, 2005) that re-maps the vertical coordinates back to their fixed positions after each time step. The model maintains smooth, thin transition zones between the Lagrangian and fixed coordinate domains.

One advantage an LVD model is that level $p$ coordinates can be used in regions of sloping topography without the numerical difficulties encountered by $\mathrm{z}$ coordinate models such as the Modular Ocean Model (MOM). MOM is an Eulerian Vertical Dynamics (EVD) model that uses the continuity equation to diagnose vertical velocity and numerical difficulties in representing the step-like structure of the sloping bottom must be reduced by employing special numerical techniques (e.g. Adcroft et al., 1997). Instead, HYCOM handles the intersection of level $p$ coordinates with the bottom (where layers collapse to zero thickness) in exactly the same manner as for isopycnic coordinates. Given that either $p$ or $\sigma$ coordinates can be used in shallow water regions, special tests were conducted to determine that level $p$ coordinates are the optimum choice (Appendix). For this study, $p$ 
coordinates are used over the continental shelf except within the $10 \mathrm{~m}$ isobath where the upper three layers are permitted to deform to $\sigma$ coordinates to maintain vertical resolution all the way to the coast (the $2 \mathrm{~m}$ isobath).

The model contains several vertical mixing choices (Halliwell, 2004), with the KProfile Parameterization (KPP; Large et al., 1994) being used in the present study. The original KPP mixing model evaluated by Halliwell (2004) did not contain an explicit parameterization of the bottom boundary layer, but one has since been added. The procedure is the same as for the surface boundary layer, first diagnosing the turbulent boundary layer thickness, and then estimating $K$ profiles for momentum and scalars at model interfaces that smoothly match the interior profiles above. In regions where the surface and bottom boundary layers overlap, the largest $K$ values are chosen at each interface. At the bottom, of course, there are no normal mass fluxes while the only heat fluxes are provided by penetrating shortwave radiation that heats the bottom surface, a negligible effect except in very shallow water. Bottom friction velocity $u_{b} *$ is the dominant parameter governing the diagnosed bottom boundary layer thickness, and thus the magnitude of the diagnosed $K$ values which are linearly proportional to this thickness.

\section{Data Assimilative GODAE Products}

Products from the evolving ocean nowcast-forecast system under development by the U. S. Navy (e.g. Chassignet et al., 2006; 2007) provide the initial and boundary fields in which the coastal simulations are nested. The initial incarnation of this system (ATL-OI) was run in the Atlantic basin at a resolution of $0.08^{\circ}$. It employed optimum interpolation (OI) to assimilate sea surface height anomaly (SSHA) from satellite altimetry, with the Cooper and Haines (1996) technique providing downward projection of information to constrain temperature and salinity profiles. Specifically, the two-dimensional Modular Ocean Data Assimilation System (MODAS) $0.25^{\circ}$ SSHA analysis (Jacobs et al., 2001; Fox et al., 2002) is assimilated daily. To generate these SSHA maps, real time satellite altimeter data [GEOSAT-Follow-On (GFO), ENVISAT, and Jason-1] are analyzed at the Altimeter Data Fusion Center (ADFC) at NAVOCEANO. In addition to SSHA, SST is assimilated by relaxing model fields to the daily MODAS $0.125^{\circ} \mathrm{SST}$ analysis which uses daily Multi-Channel Sea Surface 
Temperature (MCSST) data derived from the 5-channel Advanced Very High Resolution Radiometers (AVHRR).

The two other hindcast products evaluated herein both use the Navy Coupled Ocean Data Assimilation (NCODA) system. NCODA is an oceanographic version of the multivariate optimum interpolation (MVOI; Cummings, 2005) technique widely used in operational atmospheric forecasting systems. The NCODA system assimilates satellite altimetry track-by-track and SST directly from orbital data using model forecasts as the first guess. The system assimilates more data types than the previous OI system. However, since the availability of in-situ observations is generally very limited in the open Gulf (e.g., ARGO floats are usually not present), the NCODA assimilation in this region still relies primarily on satellite altimetry and SST measurements. As for the OI system, the Cooper and Haines (1996) algorithm is used to constrain temperature and salinity profiles. In both the NCODA and OI systems, the impact of altimetry assimilation is tapered to zero toward the coast between the middle and upper regions of the continental slope. This tapering does not degrade the representation of the LC along with its associated warm rings and cold eddies since these features are sufficiently far offshore to be fully constrained by the data assimilation. In all assimilation systems, the model runs free in the absence of observations.

The two incarnations of the NCODA system evaluated herein were run in the Gulf of Mexico (GoM-NCODA) and globally (GLB-NCODA). The regional GoMNCODA represents the initial test of the NCODA system and was run at a resolution of $0.04^{\circ}$. The non-assimilative (GoM-free) simulation that is also evaluated herein was run in the identical domain. Both GoM-NCODA and GoMfree were nested in a climatology generated from a multi-year, climatologicallyforced, $0.08^{\circ} \mathrm{HYCOM}$ Atlantic Ocean simulation. Kourafalou et al. (2008, this issue) provides additional information on both of these products. For all dataassimilative hindcasts used herein, the assimilation tends to situate the $\mathrm{LC}$ along with adjacent rings and eddies in the correct location (Chassignet et al., 2005; Halliwell and Shay, 2008). However, the climatological boundary conditions used for GoM-NCODA ensure that LC transport variability associated with the basinscale wind-driven gyres and with the Atlantic Meridional Overturning Circulation 
is incorrectly represented. In contrast, GLB-NCODA produces LC transport fluctuations that more accurately represent variability associated with the offshore gyre and overturning variability. Comparison between the simulations nested in GoM-NCODA and GLB-NCODA therefore highlights the impact of these transport differences on the nested models.

\section{Observations}

The University of South Florida has implemented a real-time Coastal Ocean Monitoring and Prediction System (COMPS; http://comps.marine.usf.edu) for the WFS. COMPS consists of an array of instrumentation both along the coast and offshore, combined with numerical circulation models, and builds upon existing in-situ measurements and modeling programs funded by various state and federal agencies. An array of offshore buoys measure current, temperature, salinity, and meteorological parameters, with satellite telemetry of the data to the shore. For the present study along with the South Florida study of Kourafalou (2008, this issue), velocity profile observations are obtained from 9 ADCP moorings $\mathrm{C} 10$ through C19 (Figure 1) while sea surface temperature is obtained from several of them. Tidal variability (He and Weisberg, 2002) was removed from these records prior to analysis since tidal forcing was not present in the model simulations. Velocity measurements are recorded hourly at depth intervals of $1 \mathrm{~m}$, with data availability as a function of depth and time summarized in Figure 2. To obtain the longest possible time series, short gaps evident in Figure 2, along with some very short gaps of one or two hours that are not visually evident in Figure 2, were filled using either linear interpolation in time or downward extrapolation in depth for those cases where near-bottom measurements dropped out. Hourly surface temperature measurements are also obtained from several of these mooring.

\section{Nested Simulations}

\subsection{Nesting Procedures}

Nested experiments are conducted within a rectangular 125x189 point Mercator mesh (Figure 1) with a horizontal resolution of $0.04^{\circ}$ east-west and $0.04^{\circ} \cos \varphi$ north-south, where $\varphi$ is longitude, resulting in a horizontal resolution of $\sim 4 \mathrm{~km}$. For nested regional studies, HYCOM is equipped with open-ocean dynamical 
boundary conditions for which no distinction is made between inflow and outflow boundaries. The method of characteristics (Browning and Kreiss, 1982, 1986) is used for the barotropic open boundary condition on velocity and pressure. At the open boundaries, buffer zones are used to relax temperature and salinity along with the baroclinic pressure and velocity fluctuations towards the fields provided by the outer models. The nesting relaxation zone is 11 grid points wide (Figure 1), with the relaxation time scales ranging from 0.1 days at the outer boundary to 24 days at the interior edge.

The topography for the nested WFS domain was extracted directly from the topography used at the Naval Research Laboratory to run both the GoM-free and GoM-NCODA outer models. This topography extends to the $2 \mathrm{~m}$ isobath and contains corrections for passages in the Florida Keys. Since the GoM-free and GoM-NCODA nested experiments used the same grid points as the outer models within the WFS domain, horizontal interpolation of outer model fields to the nested model grid was not required. Both ATL-OI and GLB-NCODA were run at half the resolution of the other outer models with their grid points co-located with every other grid point of the high resolution grid. Thus, horizontal interpolation of outer model fields to every other grid point of the nested model was required. Also, the minimum coastline isobaths of $20 \mathrm{~m}$ for ATL-OI and $10 \mathrm{~m}$ for GLBNCODA required the extrapolation of outer model fields to the shallower nested domain grid points. For both ATL-OI and GLB-NCODA, a small number of deep layers with target densities set to represent the densest waters found in the Atlantic and global oceans were discarded since water of these densities do not exist in the GoM.

Nesting fields are available from the outer model once per day. Linear temporal interpolation of these fields must therefore be performed during model runs to execute the boundary conditions at each baroclinic time step. Vertical resolution is an important issue for the nested models because the vertical coordinate strategy for HYCOM in the stratified open ocean is to limit the thickness of the nearsurface fixed $p$ coordinate domain to maximize the ocean volume represented by isopycnic coordinates. This strategy provides poor vertical resolution above the bottom over the middle and outer continental shelf so that the bottom boundary 
layer cannot be resolved. Before nesting the coastal models, the thickness of the nearsurface $p$ coordinate domain is expanded by adding additional layers with light target densities to the outer model fields (Table 2). The nested models are then run with these same vertical coordinates.

\subsection{Experimental Procedures}

The set of four experiments to be analyzed are listed in Table 1. Since we did not control how the outer model runs were conducted, there are several important differences between the nested and outer model runs. The nested models are forced by higher-resolution atmospheric fields; specifically fields obtained from a regional coupled ocean-atmosphere simulation performed using the Coupled Ocean-Atmosphere Mesoscale Prediction System (COAMPS; Hodur et al., 2002) with a horizontal resolution of $27 \mathrm{~km}$. The outer models were forced by fields obtained from the 1.0 degree NOGAPS atmospheric model with the exception of GLB-NCODA, which was forced with the 0.5 degree NOGAPS model. In all nested experiments except GLB-NCODA, the outer model provided 20 vertical layers in the northeastern GoM while the nested experiments were run with six additional layers to increase the thickness of the fixed coordinate domain (Table 2). In GLB NCODA, the outer model provided 28 vertical layers in the northeastern GoM while the nested experiment was run with four additional layers (Table 2). The nested experiments were all run using KPP mixing with bottom boundary layer parameterization while the outer models were run using either KPP without a bottom boundary layer parameterization or the Goddard Institute for Space Studies (GISS; Canuto et al., 2002) level 2 turbulence closure. The nested experiments were run with the latest HYCOM version that contained numerous improvements over the code used by the outer models, particularly with respect to the older ATL-OI hindcast.

GLB-NCODA differs in another important aspect from the other outer models. It was run using a $200 \mathrm{hPa}$ reference pressure for layer potential density instead of the surface $(0 \mathrm{hPa})$ reference used in earlier hindcasts. This choice improves representation of the vertical structure of the thermohaline overturning circulation. The same $200 \mathrm{hPa}$ reference pressure was used in the GLB-NCODA nested simulation because conversion to a different reference pressure makes it 
impossible to preserve isopycnic target densities in model layers. Although horizontal pressure gradients over the shelf will be somewhat less accurate, the inability to preserve isopycnic target densities in isopycnic layers when potential density is converted to a new reference value is also problematic. This issue will be a subject of further research.

All nested experiments were initialized with outer model fields at 0000 UTC on 1 January 2004 and run through 31 December 2005. Model time steps are six minutes for the baroclinic mode and 12 seconds for the barotropic mode. Threedimensional simulated fields were archived every three hours as a compromise between disk storage and aliasing of near-inertial variability. To evaluate nested simulations at the locations of the COMPS moorings, model runs were seeded with synthetic instruments that sample model fields at exactly the same locations and depths at which the observations are available, e.g. at $1 \mathrm{~m}$ intervals for velocity components and at the surface (model layer 1) for surface temperature. Variables sampled by the synthetic instruments are saved once per hour to match the observations. Prior to analysis, all observed and simulated time series are lowpassed using the MATLAB Chebyshev-2 filter with a half-power point of approximately 40 hours to focus on synoptic and longer-period variability.

\section{Sensitivity of Velocity to Outer Model Choice}

\subsection{Surface Flow}

Two-year mean surface velocity fields (Figure 3) reveal differences among the four nested simulations. The mean LC path is nearly identical among the three simulations nested in data-assimilative outer models, with the core of the current flowing southeastward into the domain near $25^{\circ} \mathrm{N}$, then turning eastward to follow the same path through the Florida Straits. The mean path in GoM-free differs from the other three as the core of the LC enters the domain near $26^{\circ} \mathrm{N}$, turns southward at the SW end of the WFS, then eastward through the Florida Straits. Effects of the different paths are clearly evident in the large velocity differences that exist between GoM-free and GoM-NCODA (Figure 3). Although the mean path is very similar among the three simulations nested in data-assimilative outer models, GLB-NCODA differs from the other two in that the surface velocity magnitude in 
the LC is about $30 \%$ smaller, resulting in the large velocity differences that exist between GoM-NCODA and GLB-NCODA (Figure 3). These differences are not confined to the LC core. Mean flow along the entire WFS outer shelf, and to a lesser extent along the entire middle shelf, is more northward in GLB-NCODA than in GoM-NCODA. This is the expected flow difference pattern if a weaker LC adjacent to the Dry Tortugas induces weaker southward flow over the outer WFS. Farther offshore, mean flow is more southward in GLB-NCODA than in GoMNCODA. Thus, the combined contribution of the basin-scale gyre and overturning circulations to LC transport, which is different between GoM-NCODA and GLBNCODA and incorrectly represented in GoM-NCODA, may have a significant impact on WFS circulation.

The potential importance of LC Dry Tortugas intrusion events is investigated by documenting the strongest event identified in the model simulations, occurring over 14-31 October 2004. Mean velocity fields averaged over this time interval clearly reveal the impact of this event, which is strongest in GoM-NCODA (Figure 4). In GoM-NCODA, the core of the LC enters the domain between $25^{\circ}$ and $26^{\circ} \mathrm{N}$ and then turns abruptly southward over the continental slope at the SW end of the WFS, providing strong flow immediately adjacent to the shelfbreak. Associated with this pattern is strong southward flow over the outer shelf that extends from the SW end of the WFS (near $25^{\circ} \mathrm{N}$ ) northward to $28^{\circ} \mathrm{N}$. Northward flow is also present farther offshore that turns eastward and then southward near $28^{\circ} \mathrm{N}$ to feed the outer shelf southward flow. This pattern is not present at all in GoM-free because the LC follows a zonal path and does not impinge against the SW end of the WFS. The LC does follow similar paths in the three experiments nested in data-assimilative outer models, but both ATL-OI and GLB-NCODA induce a much weaker southward flow over the outer shelf. The velocity difference map between ATL-OI and GoM-NCODA shows that the southward flow of the LC was slightly farther offshore near $25^{\circ} \mathrm{N}$ in ATL-OI so that the LC may have been less effective in inducing the southward outer shelf flow. This is also true for GLB-NCODA, although the weaker LC flow in the GLB-NCODA outer model probably contributed to this difference. Unfortunately, this event could not be validated because it occurred at a time when the outer shelf moorings C16 and C18 did not collect observations (Figure 2). 


\subsection{ADCP Moorings}

\subsubsection{Inner and Middle Shelf}

Six ADCP moorings are analyzed, which in order of increasing distance from the coast are $\mathrm{C} 15, \mathrm{C} 17, \mathrm{C} 12, \mathrm{C} 13, \mathrm{C} 16$, and $\mathrm{C} 18$ (Figure 1). $\mathrm{C} 19$ is analyzed in Kourafalou et al. (2008, this issue) and is not considered here. Vector velocity was rotated so that $u$ and $v$ represents the along- and across-shore components $\left(15^{\circ}\right.$ for $\mathrm{C} 12$, $\mathrm{C} 15$, and $\mathrm{C} 16 ; 10^{\circ}$ for $\mathrm{C} 13$; no rotation for $\mathrm{C} 17$ and $\left.\mathrm{C} 18\right)$. Taylor (2001) diagrams are used to statistically compare observed and simulated $v$ fluctuations at these moorings at the depths and time intervals marked by the horizontal red lines in Figure 2. At each mooring, all time series were normalized by the rms amplitude of the observed time series so that the same Taylor diagram could be used for all six moorings (Figure 5).

At the two moorings closest to the coast (C15 and C17), little difference exists among the four experiments (Figure 5). The correlation coefficients range from 0.85 to 0.90 at $\mathrm{C} 15$ and are near 0.7 at $\mathrm{C} 17$. Given that the normalized rms amplitude of the observed time series is 1.0, the normalized rms amplitudes of the four experiments are also very close to 1.0 , demonstrating that the simulated $v$ fluctuations have amplitudes very close to the observed value. The rms differences between the four experiments and observations are all near 0.5 . The closeness of these statistics among all four experiments results in closely-spaced points on the Taylor diagram (Figure 5). Similarity among the four experiments is also high at $\mathrm{C} 17$ which is located farther from the coast than $\mathrm{C} 15$, but the simulations are all less accurate. Correlation coefficients are all close to 0.7. The rms amplitudes of simulated $v$ are again near 1.0, but the rms differences between the four experiments and observations are about 0.8 . The close statistical similarity among the four experiments at both $\mathrm{C} 15$ and $\mathrm{C} 17$ (Figure 5) demonstrates that the choice of outer model has negligible influence on velocity fluctuations over the inner shelf.

At the two mid-shelf moorings $\mathrm{C} 12$ and $\mathrm{C} 13$, there is more scatter among the four experiments in the Taylor diagrams (Figure 5). However, this scatter is still relatively small and the choice of outer model has only a small influence on the 
quality of the simulations. Correlation coefficients range from 0.5 to 0.7 . The rms amplitudes of simulated $v$ range from 1.1 to 1.3 , so the model tends to produce fluctuations that are larger than observed. The rms differences between the four experiments and observations are all close to 1.0. This decrease of correlation with distance from the coast is verified in maps of the surface velocity vector correlation coefficient between GoM-NCODA and the other three nested experiments (Figure 6). Correlation magnitudes between pairs of nested experiments exceed 0.9 over the inner shelf, and then decrease steadily over the middle and outer shelf to $\sim 0.5$ near the shelfbreak. Velocity variability over the inner shelf is dominated by deterministic wind-driven variability that is nearly identical among the four nested experiments. This dominance gradually decreases with distance from the coast.

\subsubsection{Outer Shelf}

The scatter among the experiments in the Taylor diagrams (Figure 5) is largest at outer shelf moorings $\mathrm{C} 16$ and C18. At both of these moorings, GLB-NCODA produced $v$ fluctuations that are significantly closer to the observations than the other nested experiments. The correlation for GLB-NCODA is statistically significant $(\approx 0.6)$ at both moorings while the correlations for the other experiments are statistically insignificant. Statistical insignificance is expected between GoM-NCODA and GoM-free because the LC and adjacent eddies are incorrectly represented by the latter experiment. This is illustrated in the surface velocity vector correlation map between these two experiments where correlation magnitude is insignificant everywhere offshore of the shelfbreak (Figure 6). In contrast, offshore correlation magnitude between GOM-NCODA and both ATLOI and GLB-NCODA ranges from 0.7 to 0.8 along the LC path between the western boundary and the Dry Tortugas. Although GoM-NCODA and GLBNCODA use the identical assimilation system, the correlation magnitude fails to exceed 0.8 because the LC transport fluctuations differ substantially between the two outer models. Results from the Taylor diagram analysis suggest that GLBNCODA provides the most realistic boundary conditions.

Differences among experiments over the outer shelf are further illustrated by timedepth plots of $v$ at $\mathrm{C} 16$ from observations and from experiments GoM-free and 
GLB-NCODA (Figure 7). Fluctuations in $v$ are dominated by time scales of one week to one month, and the visual similarity among the fluctuation events between observations and GLB-NCODA is evident. In contrast, fluctuations produced by GoM-free display little resemblance to observations, and have a southward mean flow bias relative to both observations and GLB-NCODA.

To further explore why GLB-NCODA is more realistic, two time intervals are analyzed where alongshore flow in the same direction was observed simultaneously at both C16 and C18. During 26 January to 14 February 2005, northward flow is observed simultaneously at both moorings (Figure 8). A map of surface velocity from GLB-NCODA averaged over this same time interval indicates that northward flow exists over the outer shelf from $28^{\circ} \mathrm{N}$ southward to the Dry Tortugas where a cyclonic eddy associated with the LC is producing northward flow along the shelfbreak (Figure 8). This pattern essentially represents a cyclonic eddy intrusion event at the shelfbreak near the Dry Tortugas that produces alongshore flow along the outer shelf of opposite sign to the classic LC intrusion event. Paluszkiewicz et al. (1983) documented a similar cyclonic eddy intrusion event. During the second time interval (26 February to 16 March 2005), southward flow is observed at both $\mathrm{C} 16$ and $\mathrm{C} 18$ (Figure 8). The mean surface velocity from GLB-NCODA indicates that meandering southward flow exists over the outer shelf along the entire WFS (Figure 8). By this time, the cyclonic eddy has moved eastward and the LC is situated adjacent to the shelfbreak to produce a classic LC intrusion event.

These outer shelf results are not significantly impacted by the different atmospheric forcing used to drive the outer and nested models. Experiments GoMNCODA and GLB-NCODA were re-run using the original atmospheric forcing that forced the outer motels, $1.0^{\circ}$ NOGAPS for the former and $0.5^{\circ}$ NOGAPS for the latter. Maps of surface velocity averaged from 26 February to 16 March for the GLB-NCODA experiments driven by COAMPS and NOGAPS are compared in Figure 9. Little difference is observed in the outer shelf and offshore flow patterns, demonstrating insignificant impact from the change in atmospheric forcing. Little differenced in mean surface velocity over the outer shelf and slope was also observed for the GoM-NCODA case (not shown). 
The boundary conditions not only need to constrain the LC transport and path near the Dry Tortugas to accurately reproduce LC intrusion events, but also must constrain the passage of cyclonic eddies that can induce alongshore currents of opposite sign. For this several-week interval during early 2005, the GLB-NCODA boundary conditions successfully constrained the LC and the associated cyclonic eddy to reproduce the alongshore flow reversals that actually occurred over the WFS. Cyclonic eddies such as the one considered here continue on to form the socalled "Tortugas Gyres" that significantly impact circulation in the Florida Straits south of the Florida Keys. The impact of these events, including this particular cyclonic eddy, on circulation in the Florida Straits, is studied further in Kourafalou et al. (2008, this issue).

\section{Sensitivity of Temperature to Outer Model Choice}

Sea surface temperature time series available from surface instruments on some of the ADCP moorings are examined to determine to what extent they are sensitive to the different boundary conditions and to determine if improvements can be realized by nesting in data-assimilative ocean hindcasts (Figure 10). As for the ADCP observations, the temperature time series have gaps limiting time intervals that can be analyzed.

Relatively long time series with minimal gaps are available simultaneously at the two inner-shelf moorings C10 and C14 from December 2004 through December 2005 (Figure 10a,b). All experiments reproduce the annual cycle of surface temperature variability with reasonable fidelity. Relatively small differences are expected because surface temperature is expected to approximately track air temperature given that bulk formula are used to calculate surface turbulent heat flux during model runs and because the same atmospheric forcing fields drive all of the experiments. Differences among the models are very small from late spring through mid autumn as expected. However, differences become substantially larger $\left(1-2^{\circ} \mathrm{C}\right)$ during the cold season when strong atmospheric forcing events mix deeper water up to the surface and weaken the surface temperature constraint imposed by the atmospheric forcing. The offshore boundary conditions apparently do exert a significant influence on temperature at inner shelf stations although it is 
only detected at the surface when vertical mixing is strong. Thermal differences imposed at the outer boundary will influence the temperature of offshore waters that are exchanged with shelf waters across the shelfbreak. The interplay of flow variability over the shelf due to both atmospheric and offshore forcing can then transmit these temperature anomalies throughout the WFS, with the frictional bottom boundary layer likely playing an important role in cross-shelf transport (Weisberg et al., 2005).

Farther offshore, time series at moorings C12, C13, and C17 for mid-September through early December 2005 demonstrate that the model reproduces the fall cooling with reasonable fidelity (Figure 10c,d,e). Temperature at $\mathrm{C} 12$ and $\mathrm{C} 13$ are $>1^{\circ} \mathrm{C}$ too cold during the first half of the time interval, but are in better agreement with observations after hurricane Wilma passes in late October. Model temperatures are in good agreement with one distinct exception: temperatures produced by the GoM-free experiment become too cold after the first of November. Temperature time series are also presented for two winter time intervals, at C12 during winter 2004 (Figure 10f) and at C17 during winter 2005 (Figure 10g). Although the models reproduce synoptic fluctuations with reasonable fidelity, the relatively large winter differences among the nested experiments are clearly evident. Also evident again is the tendency for the GoMfree experiment to produce temperatures that are too cold.

The cold SST bias produced by GoM-free during the cold season at mid-shelf moorings is explored further by analyzing simulated temperature variability as a function of depth and time at mid-shelf mooring C12 (Figure 11). The depth-time plot for temperature from experiment GoM-NCODA clearly reveals the two seasonal cycles along with abrupt mixing events during late summer and fall of both years due to frequent hurricane passage. The other three panels in Figure 11 show the temperature difference between the other three experiments and GoMNCODA. Experiment GoM-free tends to be substantially colder than the other three experiments. The source of this problem is that the non-assimilative GoMfree outer model has a persistent cold bias in the upper ocean that was substantially corrected by the data assimilation used in the other outer models (not shown). Experiment GoM-free was therefore initialized with fields that had a cold 
bias, and the boundary conditions maintained this cold bias relative to the other experiments throughout the two year run. Given that GoM-free produces isotherms near the shelfbreak that are higher in the water column that the other experiments, water exchanges across the shelfbreak will lead to colder water moving onto the WFS. Weisberg et al. (2005) discusses scenarios where the interplay of atmospheric and offshore forcing can transmit offshore water with abnormal properties over most of the WFS, even well onto the inner shelf. It is therefore important that the chosen outer model have a reasonably accurate upper ocean temperature structure. The present results document the advantages of nesting within outer models where data assimilation has improved the upperocean structure of temperature (and presumably other water properties).

\section{Conclusions}

We achieved limited success in detecting positive impacts of nesting a coastal ocean model of the WFS within data assimilative ocean hindcasts during 20042005. Concerning flow variability over the WFS, the ability of the outer model to accurately constrain both the path and flow velocity of the LC and associated eddies off the southwestern end of the WFS had a positive impact on the simulation of alongshore flow along the outer WFS. Experiment GoM-free nested in a non-assimilative outer model did not reproduce alongshore flow events that were observed at two outer shelf ADCP moorings while experiment GLBNCODA reproduced them most realistically. Although GoM-NCODA used the same observations and assimilation system as GLB-NCODA, the former was a regional model nested in Atlantic basin climatology that did not contain realistic LC transport variability associated with the wind-driven gyre circulation and the Atlantic Meridional Overturning Circulation. This absence of realistic transport variability is one possible reason why the GoM-NCODA nested simulation produced less realistic outer shelf flow variability than GLB-NCODA. Since the impact of offshore flow variability tends to be confined to the outer shelf due to the Taylor-Proudman constraint, and since deterministic wind-driven flow variability gradually becomes dominant toward the coast, the choice of outer model did not significantly influence flow variability over the middle and inner shelf. 
Another positive impact was observed in the representation of temperature over the WFS. The non-assimilative outer model GoM-free had a significant cold bias in the upper ocean relative to the three data-assimilative outer models. This cold bias was presumably communicated across the WFS during the two-year experiments because the existence of surface and bottom Ekman layers breaks the Taylor-Proudman constraint and permits efficient cross-shelf exchanges of water properties. The cold bias was nearly always present below the surface mixed layer during the 2004-2005 time interval, but was only detectable in moored surface temperature measurements during the cold season when strong atmospheric forcing mixed the cold water up to the surface. It is very important for the outer model to accurately represent the upper-ocean temperature (along with salinity and density) structure so that offshore water with the correct properties is entrained onto the WFS.

The present analysis also contributed to the ongoing development of HYCOM as a coastal ocean model. In particular, it was demonstrated that the use of level $p$ coordinates over the continental shelf and shelfbreak region instead of $\sigma$ coordinates can reduce pressure gradient errors (Appendix) and does not require special numerical techniques to represent sloping topography that are necessary for Eulerian Vertical Dynamics models such as MOM.

Although we are encouraged by the ability to detect positive impacts of nesting in data-assimilative outer models, the results presented herein are based on limited space-time observational coverage. This is particularly true for the velocity measurements available along the outer shelf. Further study is necessary to accurately quantify the importance of the intrusion of the LC and associated cyclones at the shelfbreak and near the Dry Tortugas. It is clear from the present analysis that accurate representation of the LC path and transport by the chosen outer model is critically important to achieve this goal.

Acknowledgements: G. Halliwell was supported by the Office of Naval Research under award number N000140510892. Development and evaluation of the HYCOM nowcast/forecast system was supported by ONR under award number N000140410676. R. Weisberg was also supported by this grant along with ONR grant numbers N00014-05-1-0483 and N00014-02-1-0972, plus FFWCC/FMRI grant number S 7701620071 . We acknowledge the USF-CMS Ocean Circulation 
Group staff, R. Cole, J. Donovan, J. Law, C. Merz, R. Russell, and V. Subramanian for the success of the WFS mooring program that provided the data used herein.

\section{Appendix: Vertical Coordinate Selection}

The first application of HYCOM as a coastal model (Winther and Evensen, 2006) demonstrated that the model could produce realistic circulation and water mass structure in shallow water regions. They used the standard approach for coastal regions of allowing the offshore isopycnic and nearsurface level $p$ coordinates to transition to $\sigma$ coordinates over shallow water. The classic seamount problem (e.g. Beckmann and Haidvogel, 1993) is used here to demonstrate the superiority of using $p$ instead of $\sigma$ coordinates in coastal regions with sloping topography.

The seamount domain was set up in a $360 \times 360 \mathrm{~km} f$-plane box, with $f$ set to its value at $30^{\circ} \mathrm{N}$, and uses the seamount structure of Shchepetkin and Mc Williams (2003):

$$
h(x, y)=H_{0}-H \exp \left(\frac{-\left(x^{2}+y^{2}\right)}{L^{2}}\right)
$$

where $L=5000 \mathrm{~m}, H=4500 \mathrm{~m}$, and $L=40 \mathrm{~km}$. The continuous initial density profile is exponential and roughly representative of summer density profiles observed in the subtropical Atlantic. The Burger number is $\sim 3$, an intermediate value in the range of cases considered in earlier seamount tests (e.g. Beckmann and Haidvogel, 1993; Mellor et al., 1998; Shchepetkin and Mc Williams, 2003). Twenty-two vertical layers were used for both the $p$ and $\sigma$ coordinate cases. To initialize model fields, the density value of each layer was first assigned as a function of central layer depth based on the initial continuous density profile. To assign initial $T$ and $S$ values to each layer, an exponential temperature profile roughly representative of the summer subtropical Atlantic was used to assign $T$ values at central layer depths, then $S$ values were calculated using the model equation of state. Initial cross sections of density for both vertical coordinate choices are presented in Figure 12. In addition to the two cases run with the existing Montgomery potential formulation of the pressure gradient force (MP), two additional cases were run implementing the pressure gradient formulation used in the Regional Ocean Modeling System (ROMS) ocean model (Shchepetkin and Mc Williams, 2003). 
For each of the four cases, the model was run unforced for 24 hours. The resulting currents resulted from errors in the pressure gradient force, and the effects of these errors were monitored by graphing the total kinetic energy as a function of time (Figure 12). The most rapid increase in KE occurs for the $\sigma$ coordinate, MP case. The rate of increase was much smaller for the $p$ coordinate, MP case because pressure gradient errors at any grid point are confined to the deepest layer with non-zero thickness that intersects a sloping bottom while errors exist in shallower $\sigma$ coordinate layers. A similar scenario is observed for the two ROMS cases, with the smallest rate of KE increase occurring in the $p$ coordinate case. These results demonstrate the superiority of using $p$ coordinates over sloping topography in HYCOM. Ideally, the ROMS pressure gradient formulation should also be used, but there is a significant problem in the interior isopycnic coordinate domain. If a level isopycnic layer intersects a sloping bottom, there should be zero pressure gradient force and this is achieved with high accuracy by the MP formulation. However, this situation produces adjacent grid points where the sloping bottom is shallower than the level interface at the bottom of the layer, resulting in a change of central layer depth between the grid points. Given constant density in this layer, the ROMS formulation detects a sloping density interface and produces a nonzero pressure gradient force where none should exist. Tests demonstrated that this problem more than nullified the improvements produced by the ROMS formulation in the non-isopycnic coordinate domain (not shown). Therefore, the MP formulation was retained and $p$ coordinates used for the nested coastal simulations in this study. This is a reasonable choice because the rate of $\mathrm{KE}$ increase in the seamount tests was comparable to the rate of increase for the ROMS formulation used with $\sigma$ coordinates (Figure 12).

\section{References}

Adcroft A, Hallberg R (2005) On methods for solving the oceanic equations of motion in generalized vertical coordinates. Ocean Modelling: 11; 224-233

Adcroft A, Hill C, Marshall J (1997) Representation of topography by shaved cells in a height coordinate ocean model. Mon. Wea. Rev., 125; 2293-2315. 
Barth A, Alvera-Azcárate A, Weisberg RH (2008) Benefit of nesting a regional model into a largescale ocen model instead of climatology. Application to the West Florida Shelf. Continental Shelf Res., 28; 561-573, doi:10.1016/j.csr.2007.11.004

Beckmann A., Haidvogel DB (1993) Numerical simulation of flow around a tall isolated seamount, 1, Problem formulation and model accuracy. J. Phys. Oceanogr., 23; 1736-1753

Bleck R (1998) Ocean modeling in isopycnic coordinates. Chapter 18 in Ocean Modeling and Parameterization, E. P. Chassignet and J. Verron, Eds., NATO Science Series C: Mathematical and Physical Sciences, Vol. 516, Kluwer Academic Publishers, 423-448

Bleck R (2002) An oceanic general circulation framed in hybrid isopycnic-Cartesian coordinates. Ocean Modelling 4: 55-88

Bleck R, Rooth C, Hu D, Smith LT (1992) Ventilation patterns and mode water formation in a wind- and thermodynamically driven isopycnic coordinate model of the North Atlantic. J. Phys. Oceanogr., 22,:1486-1505

Browning GL, Kreiss H-O (1982) Initialization of the shallow water equations with open boundaries by the bounded derivative method. Tellus, 34: 334-351

Browning GL, Kreiss H-O (1986) Scaling and computation of smooth atmospheric motions.

Tellus, 38A: 295-313

Canuto VM, Howard A, Cheng Y, Dubovikov MS (2002) Ocean turbulence. Part II: Vertical diffusivities of momentum, heat, salt, mass, and passive scalars. J. Phys. Oceanogr., 32: 240-264

Chapman DC, Brink KH (1987) Shelf and slope circulation induced by fluctuating offshore forcing. J. Geophys. Res., 92: 11741-11759

Chassignet EP, Smith L, Halliwell GR, Bleck R (2003) North Atlantic simulation with the hybrid coordinate ocean model (HYCOM): Impact of the vertical coordinate choice and resolution, reference density, and thermobaricity. J. Phys. Oceanogr., 33: 2504-2526

Chassignet EP, Hurlburt HE, Smedstad OM, Halliwell GR, Hogan PJ, Wallcraft AJ, Bleck R (2006) Ocean prediction with the Hybrid Coordinate Ocean Model (HYCOM). In: Ocean Weather Forecasting: An Integrated View of Oceanography, Chassignet, E.P., and J. Verron (Eds.), Springer: $413-426$ 
Chassignet EP, Hurlburt HE, Smedstad OM, Halliwell GR, Hogan PJ, Wallcraft AJ, Bleck R (2007) Ocean Prediction with the HYbrid Coordinate Ocean Model (HYCOM). J. Marine

Systems, 65: 60-83

Cooper M, Haines K (1996) Altimetric assimilation with water property conservation. J. Geophys. Res., 101: 1059-1078

Cragg J, Mitchum G, Sturges W (1983) Wind-induced sea surface slopes on the West Florida Shelf. J. Phys. Oceanogr., 13: 2201-2212

Cummings JA (2005) Operational multivariate ocean data assimilation. Q. J. R. Meteorol. Soc., 131: 3583-3604.

Fox DN, Teague WJ, Barron CN, Carnes MR, and Lee CM (2002) The Modular Ocean Data Analysis System (MODAS). J. Atmos. Oceanic Technol., 19: 240-252

Halliwell Jr. GR (2004) Evaluation of vertical coordinate and vertical mixing algorithms in the hybrid-coordinate ocean model (HYCOM). Ocean Modelling, 7: 285-322

Halliwell Jr. GR, Shay LK, Jacob SD, Smedstad OM, Uhlhorn EW (2008) Improving ocean model initialization for coupled tropical cyclone forecast models using GODAE nowcasts. Mon Wea. Rev., 136; 2576-2591

He R, Weisberg RH (2002) Tides on the West Florida Shelf. J. Phys. Oceanogr., 32; 3455-3473

He R, Weisberg RH (2003) A loop current intrusion case study on the West Florida Shelf J. Phys. Oceanogr., 33, 465-477, 2003.

Hetland RD, Hsueh Y, Leben RR, Niiler PP (1999) A Loop Durrent-induced jet along the edge of the West Florida Shelf. Geophys. Res. Lett.: 2239-2242

Hodur RM, Pullen J, Cummings J, Hong, X. Doyle D, Martin PJ, and Rennick MA (2002) The Coupled Ocean/Atmospheric Mesoscale Prediction System (COAMPS). Oceanography, 15; 88-98.

Huh OK, Wiseman WJ, Vansant LL (1981) Intrusion of Loop Current waters onto the west Florida continental shelf. J. Geophys. Res., 86: 4186-4192

International GODAE Steering Team (2000) Global Ocean Data Assimilation Experiment Strategic Plan. GODAE Report \#6, GODAE International Project Office, Bureau of Meteorology, Melbourne, Australia: 26pp 
Jacobs GA, Barron CN, Rhodes RC (2001) Mesoscale characteristics. J. Geophys. Res., 106: $19,581-19,595$

Kelly KA, Chapman DC (1988) The response of stratified shelf and slope waters to steady offshore forcing. J. Phys. Oceanogr., 18: 906-925

Kourafalou V.H., Peng G, Kang H, Hogan PJ, Smedstadt OM, Weisberg RH, Baringer MO, Meinen CS (2008). Evaluation of Global Ocean Data Assimilation Experiment products on South Florida nested simulations with the Hybrid Coordinate Ocean Model. Ocean Dynamics, submitted: this issue

Large WG, Mc Williams JC, Doney SC (1994) Oceanic vertical mixing: a review and a model with a nonlocal boundary layer parameterization. Rev. Geophys. 32: 363-403

Liu Y, Weisberg RH (2005) Patterns of ocean current variability on the West Florida Shelf using the self-organized map. J. Geophys. Res., 110: C06003, doi:10,1029/2004JC002786

Liu Y, Weisberg RH (2007) Ocean currents and sea surface heights estimated across the West Florida Shelf. J. Phys. Oceanogr., 37: 1697-1713

Marmorino GO (1983) Variability of currents, temperature, and bottom pressure across the West Florida Continental Shelf, winter 1981-1982. J. Geophys. Res., 88: 4439-4457

Mellor GL, Oey L-Y, Ezer T (1998) Sigma coordinate pressure gradient errors and the seamount problem, J. Atmos. Oceanic Technol., 15: 1122-1131

Mitchum TG, Sturges W (1982) Wind-driven currents on the West Florida Shelf. J. Phys. Oceanogr., 12: 1310-1317

Mitchum TG, Clarke AJ (1986a) The frictional nearshore response to forcing by synoptic scale winds. J. Phys. Oceanogr., 16: 934-946

Mitchum TG and Clarke AJ (1986b) Evaluation of frictional, wind forced long wave theory on the West Florida Shelf. J. Phys. Oceanogr., 16: 1029-1037

Niiler PP (1976) Observations of low-frequency currents on the West Florida Continental Shelf. Mem. Soc. Roy Sci. Leige, 6: 331-358

Paluszkiewicz T, Atkinson L, Parmentier ES, McClain CS (1983) Observations of a loop current frontal eddy intrusion onto the West Florida Shelf. J. Geophys. Res., 88: 9639-9651 
Shchepetkin AF, McWilliams JC (2003) A method for computing pressure-gradient force in an oceanic model with a non-aligned vertical coordinate. J. Geophys. Res., 108;

doi:10.1029/2001JC001047

Taylor KE (2001) Summarizing multiple aspects of model performance in a single diagram. J.

Geophys. Res., 106, 7183-7192.

Weisberg RH, Black BD, Li Z (2000) An upwelling case study on Florida's west coast. J.

Geophys. Res., 105: 11,459-11,469

Weisberg RH, Li Z, Muller-Karger F (2001) West Florida shelf response to local wind forcing: April 1998. J. Geophys. Res., 106: 31239-31262

Weisberg RH, He R (2003) Local and deep-ocean forcing contributions to anomalous water properties on the West Florida Shelf. J. Geophys. Res., 108, C6, 15, doi:10.1029/2002JC001407

Weisberg RH, He R, Kirkpatrick G, Muller-Karger F, Walsh JJ (2004) Coastal ocean circulation influences on remotely sensed optical properties: a West Florida Shelf case study. Oceanography, $17: 68-75$

Weisberg RH, He R, Liu Y, Virmani JI (2005) West Florida Shelf circulation on synoptic, seasonal, and interannual time scales. In Circulation in the Gulf of Mexico: Observations and Models, Geophysical Monograph Series 161, American Geophysical Union: pp 325-347

Winther NG, Evensen G (2006) A hybrid coordinate ocean model for shelf sea simulation. Ocean Modelling, 13; 221-237

\section{Figure Legends}

Figure 1. Locations of the West Florida Shelf COMPS ADCP Moorings C10 to C19 along with the boundaries of the nested model domain. Dashed lines outline the nesting relaxation boundary zones. The 20, 50, and $100 \mathrm{~m}$ isobaths are shown as is a schematic of the Loop Current path. Figure 2. Depth-time plot of ADCP data availability at the nine COMPS ADCP moorings in Figure 1. Depths and times with missing data are blacked out. Very short 1-2 hr gaps present at some moorings are not visible. The horizontal red bars show the depth and time range of the velocity component time series used to statistically compare the nested experiments in Figure 5.

Figure 3. Mean surface velocity field over the entire 2004-2005 time interval for, top to bottom along the left side, experiments GoM-free, GoM-NCODA, ATL-OI, and GLB-NCODA. The panels from top to bottom along the right side show the mean velocity difference between experiments GoM-free, ATL-OI, and GLB-NCODA and experiment GoM-NCODA. The velocity 
scale for the difference maps has been tripled to more clearly show the difference patterns. The $100 \mathrm{~m}$ isobath is shown.

Figure 4. Same as Figure 3, but for the time interval 14 to 31 October when a LC intrusion at the SW corner of the WFS apparently drove a strong southward jet over the outer shelf.

Figure 5. Taylor diagrams comparing the four nested experiments at six ADCP moorings. The moorings in panels (a) through (f) are arranged in order of increasing distance from the coast. The color legend for the points plotted in each panel is shown at the bottom.

Figure 6. Maps of vector correlation magnitude between 3-hourly surface velocity fields from nested experiment GoM-NCODA and each of the other three experiments: GoM-free (left), ATLOI (center), and GLB-NCODA (right). Locations of the six moorings used in the Taylor diagram analysis (Figure 5) are shown with black dots. The three northern moorings are, from offshore to coast, $\mathrm{C} 16, \mathrm{C} 12$, and $\mathrm{C} 15$. The three southern moorings are, from offshore to coast, $\mathrm{C} 18, \mathrm{C} 13$, and C17.

Figure 7. Time-depth plots of the alongshore velocity component during the first six months of 2005 at ADCP mooring C16.

Figure 8. Mean surface velocity maps from experiment GLB-NCODA (upper-left) over 26 January to 14 February 2005 when persistent northward flow was observed over the outer shelf at both moorings C16 and C18 (upper right). Mean surface velocity maps from experiment GLB-NCODA over 26 February 2005 to 17 March 2005 (lower left) when southward flow was observed at the same two moorings (lower right). The $100 \mathrm{~m}$ isobath is shown in the velocity maps.

Figure 9. Mean surface velocity fields over the time interval 26 February 2005 through 17 March 2005 from experiment GoM-NCODA (left) and a second GLB-NCODA experiment (right) that was forced by atmospheric fields from the same Navy 0.5-degree NOGAPS atmospheric model that was used to force the GLB-NCODA outer model. The $100 \mathrm{~m}$ isobath is shown.

Figure 10. Sea surface temperature time series for selected time intervals measured by surface instrumentation at the COMPS moorings. Panels (a) and (b) are for nearshore moorings $\mathrm{C} 10$ and C14 for mid-December 2004 through 2005. Panels (c), (d), and (e) are for moorings C12, C13, and C17 during fall 2005. Panels (f) and (g) are for two winter/spring intervals, C12 for 2004 and C17 for 2005. Red lines are for experiment GoM-free, green lines for GoM-NCODA, blue lines for ATL-OI, and solid black lines for GLB-NCODA. The magenta lines represent the observations.

Figure 11. Depth-time plot of temperature at mooring C12 simulated by experiment GoMNCODA (top panel) along with the temperature differences observed between experiments GoMfree, ATL-OI, and GLB-NCODA and experiment GoM-NCODA (bottom 3 panels).

Figure 12. Initial density field and vertical coordinates for the $p$ and $\sigma$ coordinate seamount tests (left). Temporal evolution of kinetic energy over the first day of integration for the four seamount tests. 
Table 1. Properties of the four nested experiments. Outer model nest refers to the product within which the outer model was nested. Outer model nest "CLIM" refers to a model-generated Atlantic Ocean climatology.

\begin{tabular}{|c|c|c|c|c|c|c|}
\hline $\begin{array}{c}\text { Nested } \\
\text { Experiment }\end{array}$ & $\begin{array}{c}\text { Horizontal } \\
\text { Grid Type }\end{array}$ & $\begin{array}{c}\text { Ref. } \\
\text { Pressure } \\
(\mathrm{hPa})\end{array}$ & $\begin{array}{c}\text { Outer } \\
\text { Model } \\
\text { Resolution }\end{array}$ & $\begin{array}{c}\text { Outer } \\
\text { Model } \\
\text { Minimum } \\
\text { Depth (m) }\end{array}$ & $\begin{array}{c}\text { Outer } \\
\text { Model } \\
\text { Nest }\end{array}$ & $\begin{array}{c}\text { Outer } \\
\text { Model } \\
\text { Mixing } \\
\text { Model }\end{array}$ \\
\hline GoM-free & Mercator & 0 & $0.04^{\circ}$ & 2 & CLIM & GISS \\
\hline GoM-NCODA & Mercator & 0 & $0.04^{\circ}$ & 2 & CLIM & GISS \\
\hline ATL-OI & Mercator & 0 & $0.08^{\circ}$ & 20 & GDEM3 & $\begin{array}{c}\text { KPP-No } \\
\text { BBL }\end{array}$ \\
\hline GLB-NCODA & Mercator & 200 & $0.08^{\circ}$ & 10 & N/A & $\begin{array}{c}\text { KPP-No } \\
\text { BBL }\end{array}$ \\
\hline
\end{tabular}


Table 2. Layer target densities (sigma units) for the four outer model products and the six nested experiments. Note that the outer and nested models have the same target densities except that six layers were added to the top of the experiments nested in a GoM outer model while four layers were added to the top of the experiment nested in the GLB model.

\begin{tabular}{|c|c|c|c|c|}
\hline Layer & $\begin{array}{c}\text { Outer Models } \\
\text { GoM-free, GoM- } \\
\text { NCODA, ATL- } \\
\text { OI }\end{array}$ & $\begin{array}{c}\text { Nested } \\
\text { Experiments GoM- } \\
\text { free, GoM- } \\
\text { NCODA, ATL-OI }\end{array}$ & $\begin{array}{c}\text { Outer Model } \\
\text { GLB-NCODA }\end{array}$ & $\begin{array}{c}\text { Nested } \\
\text { Experiment } \\
\text { GLB-NCODA }\end{array}$ \\
\hline 1 & 19.50 & 13.50 & 28.10 & 23.90 \\
\hline 2 & 20.25 & 14.50 & 28.90 & 25.10 \\
\hline 3 & 21.00 & 15.50 & 29.70 & 26.20 \\
\hline 4 & 21.75 & 16.50 & 30.50 & 27.20 \\
\hline 5 & 22.50 & 17.50 & 30.95 & 28.10 \\
\hline 6 & 23.25 & 18.50 & 31.50 & 28.90 \\
\hline 7 & 24.00 & 19.50 & 32.05 & 29.70 \\
\hline 8 & 24.70 & 20.25 & 32.60 & 30.50 \\
\hline 9 & 25.28 & 21.00 & 33.15 & 30.95 \\
\hline 10 & 25.77 & 21.75 & 33.70 & 31.50 \\
\hline 11 & 26.18 & 22.50 & 34.25 & 32.05 \\
\hline 12 & 26.52 & 23.25 & 34.75 & 32.60 \\
\hline 13 & 26.80 & 24.00 & 35.15 & 33.15 \\
\hline 14 & 27.03 & 24.70 & 35.50 & 33.70 \\
\hline 15 & 27.22 & 25.28 & 35.80 & 34.25 \\
\hline 16 & 27.38 & 25.77 & 36.04 & 34.75 \\
\hline 17 & 27.52 & 26.18 & 36.20 & 35.15 \\
\hline 18 & 27.64 & 26.52 & 36.38 & 35.50 \\
\hline 19 & 27.74 & 26.80 & 36.52 & 35.80 \\
\hline 20 & 27.82 & 27.03 & 36.62 & 36.04 \\
\hline 21 & 27.88 & 27.22 & 36.70 & 36.20 \\
\hline 22 & 27.94 & 27.38 & 36.77 & 36.38 \\
\hline 23 & & 27.52 & 36.83 & 36.52 \\
\hline 24 & & 27.64 & 36.89 & 36.62 \\
\hline 25 & & 27.74 & 36.97 & 36.70 \\
\hline 26 & & 27.82 & 37.02 & 36.77 \\
\hline 27 & & 27.88 & 37.06 & 36.83 \\
\hline 28 & & 27.94 & 37.10 & 36.89 \\
\hline 29 & & & & 36.97 \\
\hline 30 & & & & 37.02 \\
\hline 31 & & & & 37.06 \\
\hline 32 & & & & 37.10 \\
\hline
\end{tabular}




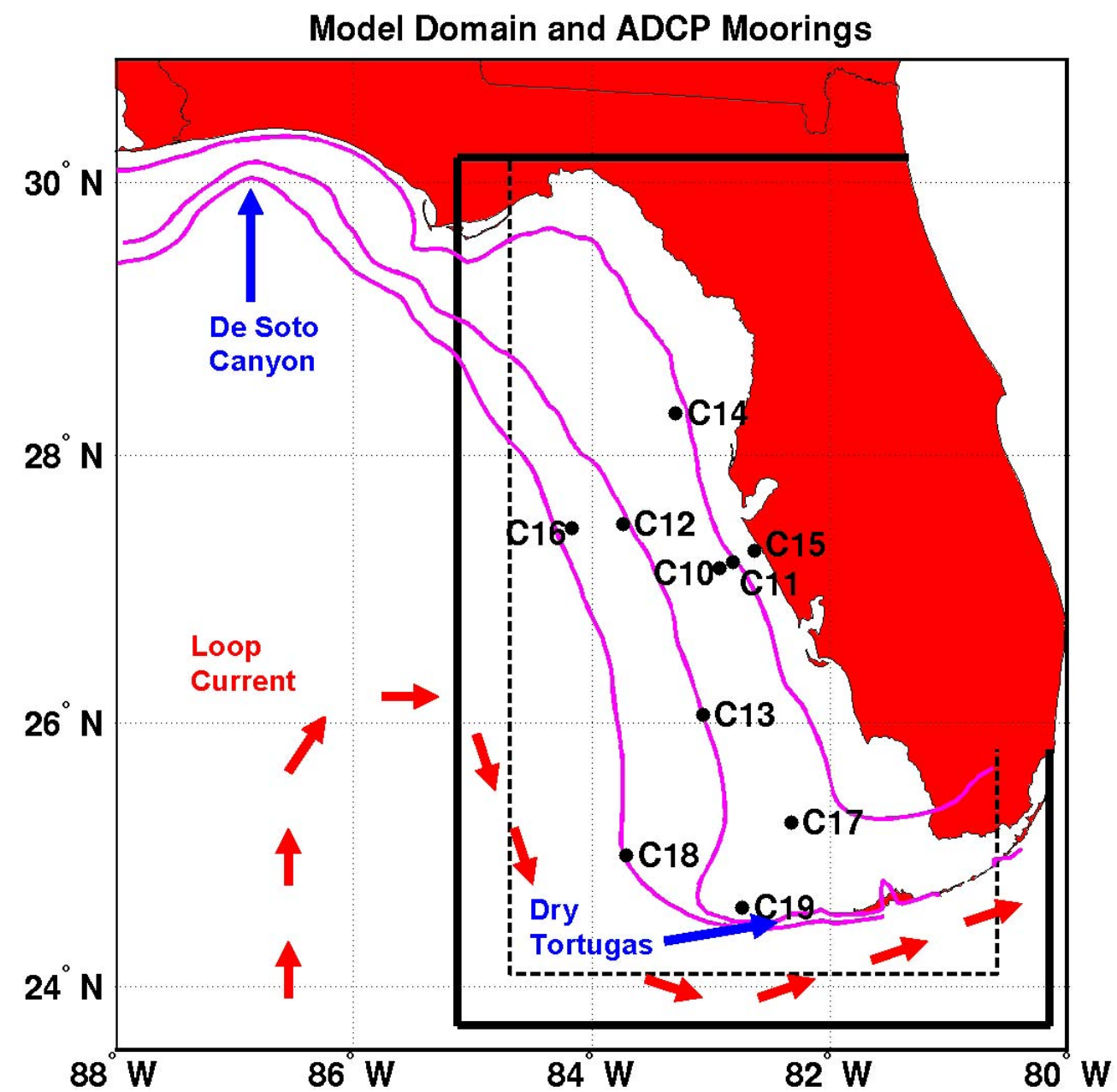

Figure 1. Locations of the West Florida Shelf COMPS ADCP Moorings C10 to C19 along with the boundaries of the nested model domain. Dashed lines outline the nesting relaxation boundary zones. The 20, 50, and $100 \mathrm{~m}$ isobaths are shown as is a schematic of the Loop Current path. 
C10

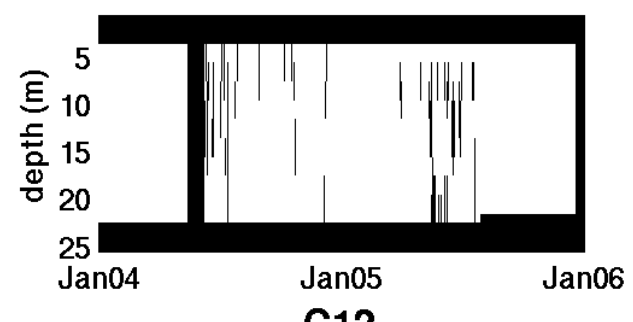

C12
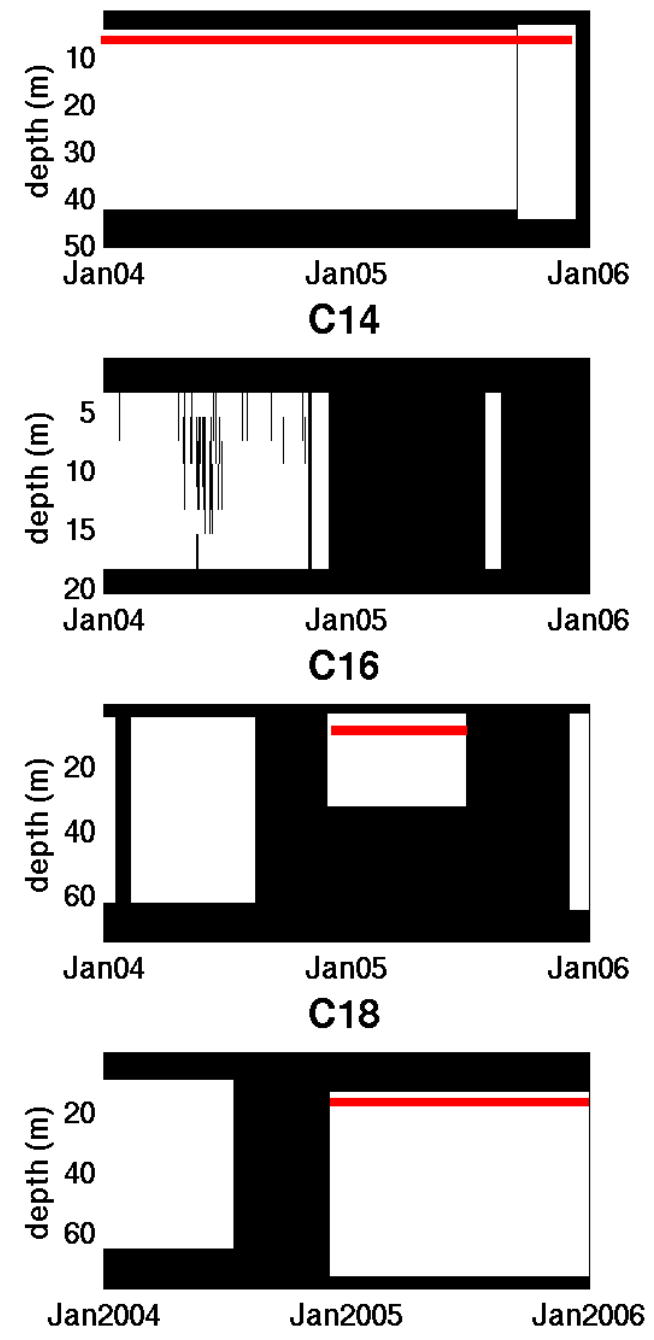

C11
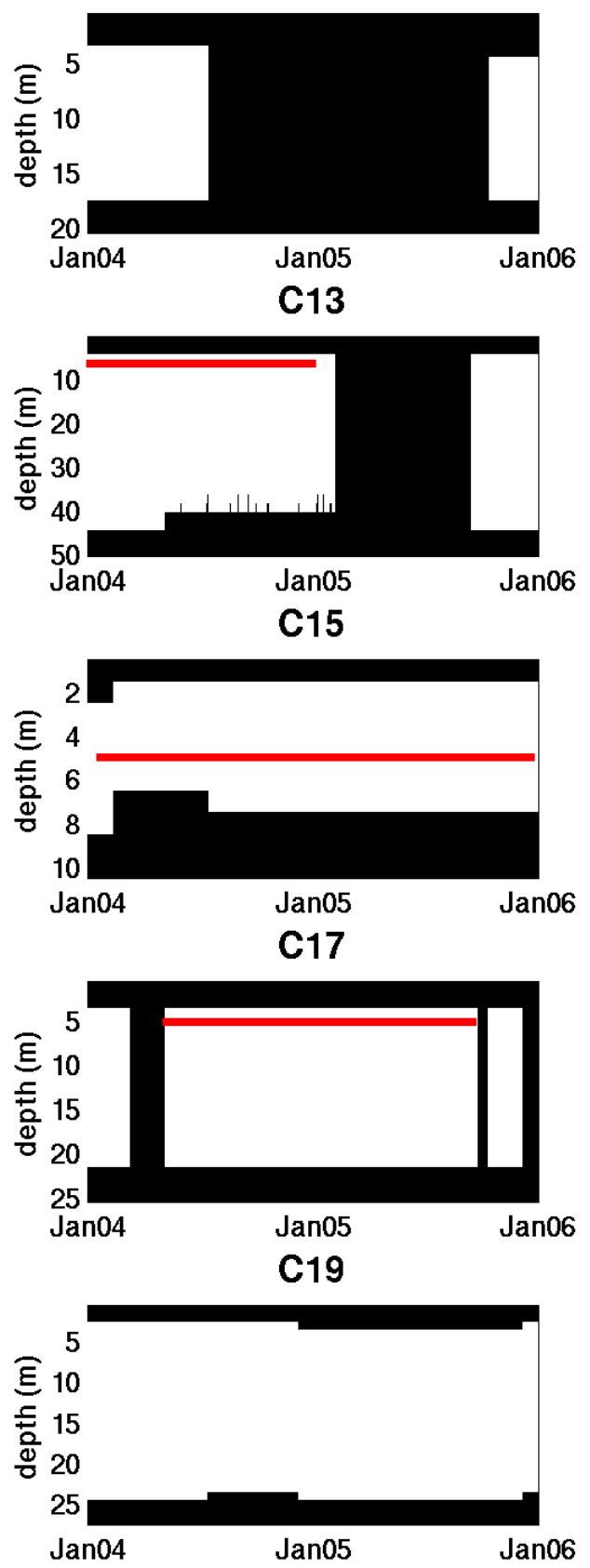

Figure 2. Depth-time plot of ADCP data availability at the nine COMPS ADCP moorings in Figure 1. Depths and times with missing data are blacked out. Very short 1-2 hr gaps present at some moorings are not visible. The horizontal red bars show the depth and time range of the velocity component time series used to statistically compare the nested experiments in Figure 5. 

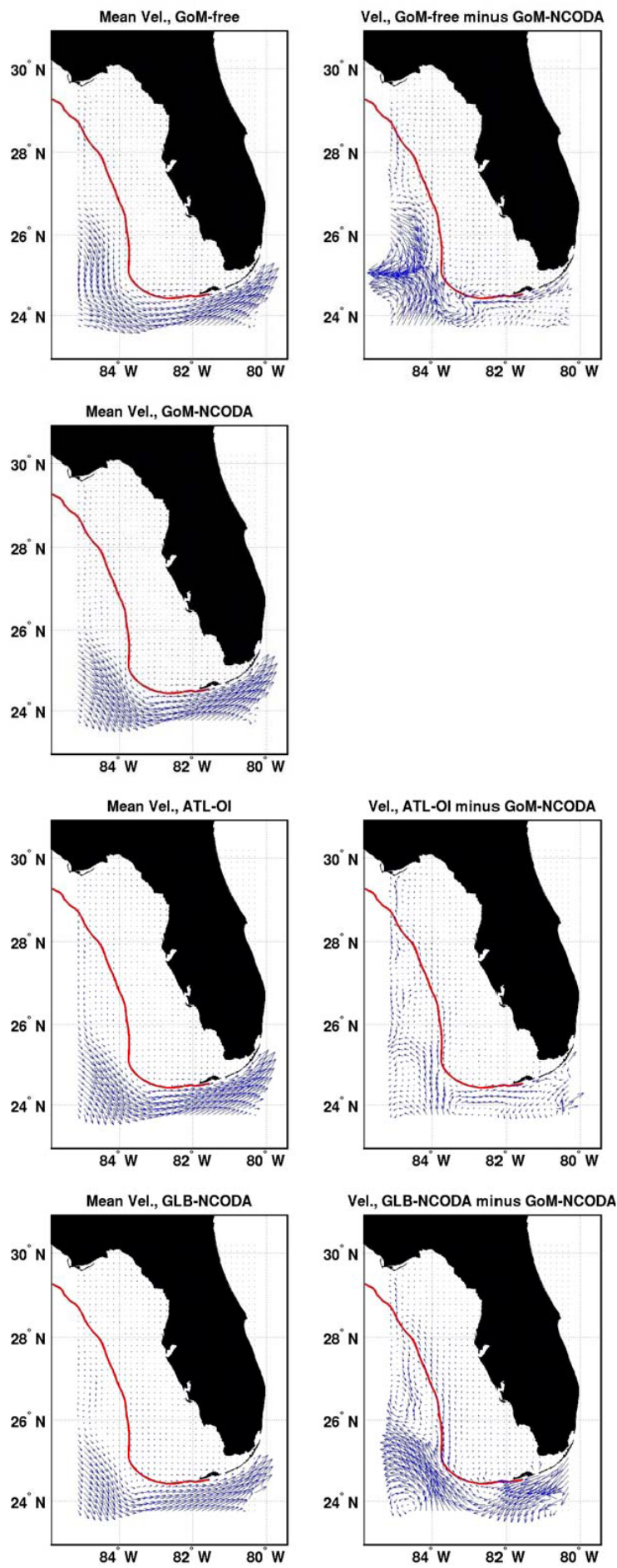

Figure 3. Mean surface velocity field over the entire 2004-2005 time interval for, top to bottom along the left side, experiments GoM-free, GoM-NCODA, ATL-OI, and GLB-NCODA. The panels from top to bottom along the right side show the mean velocity difference between experiments GoM-free, ATL-OI, and GLB-NCODA and experiment GoM-NCODA. The velocity scale for the difference maps has been tripled to more clearly show the difference patterns. The $100 \mathrm{~m}$ isobath is shown. 

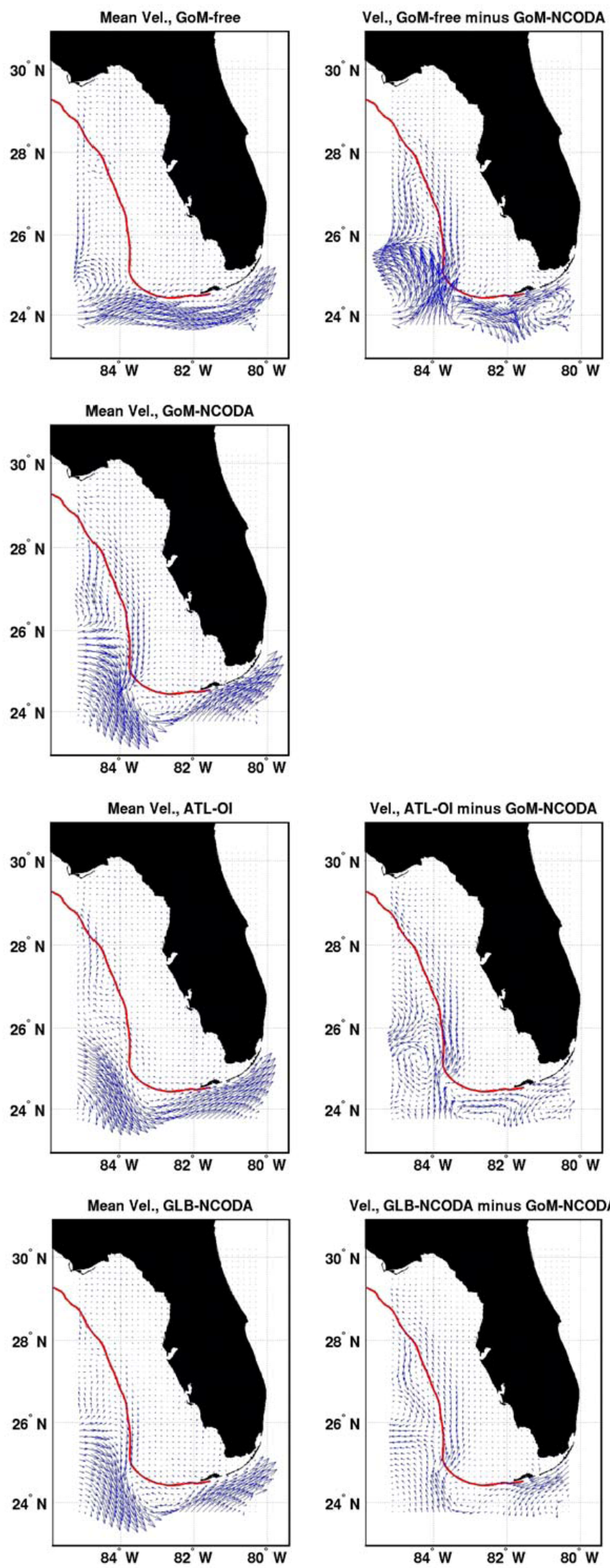
Figure 4. Same as Figure 3, but for the time interval 14 to 31 October when a LC intrusion at the SW corner of the WFS apparently drove a strong southward jet over the outer shelf.
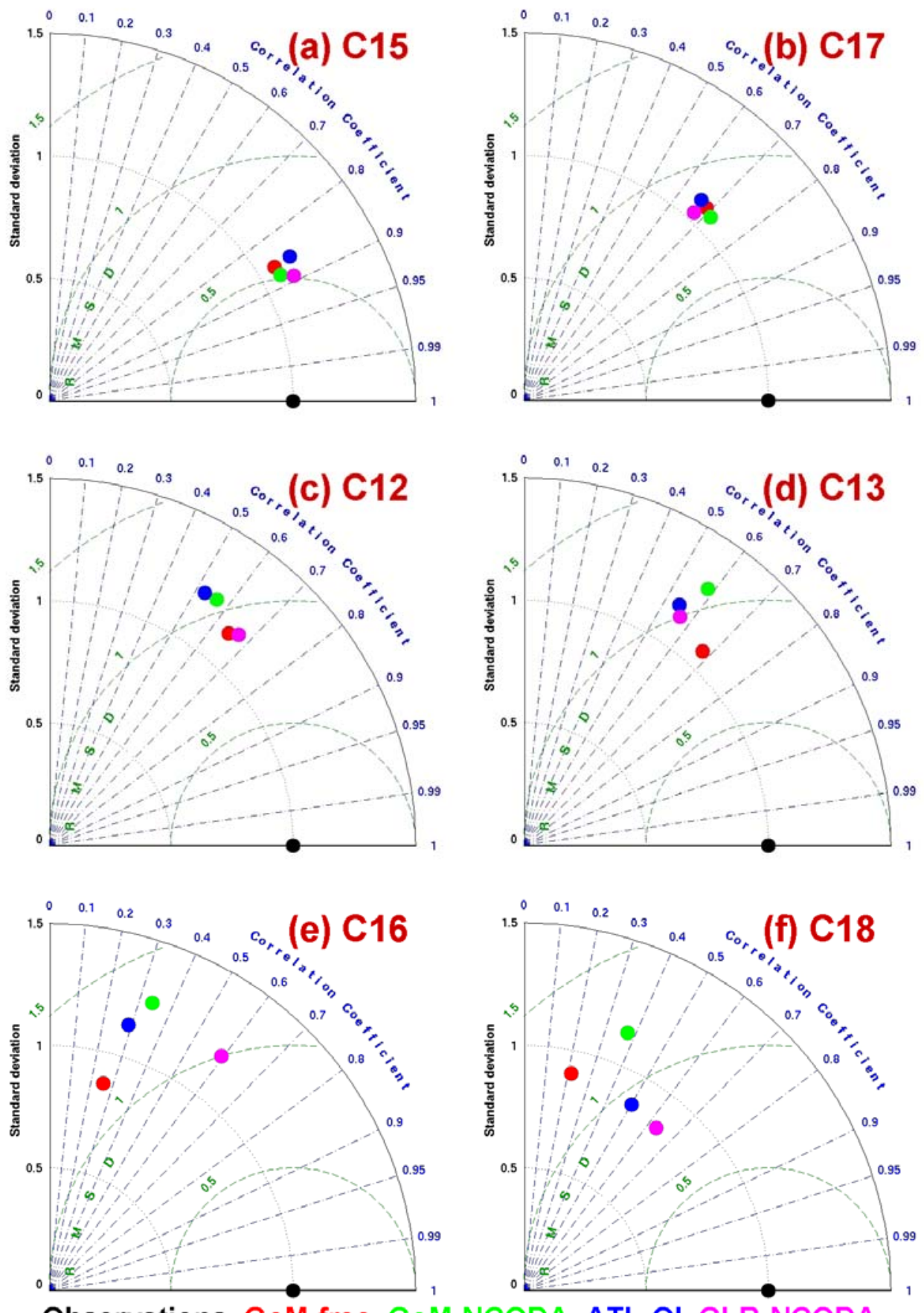

Observations, GoM-free, GoM-NCODA, ATL-OI, GLB-NCODA

Figure 5. Taylor diagrams comparing the four nested experiments at six ADCP moorings. The moorings in panels (a) through (f) are arranged in order of increasing distance from the coast. The color legend for the points plotted in each panel is shown at the bottom. 


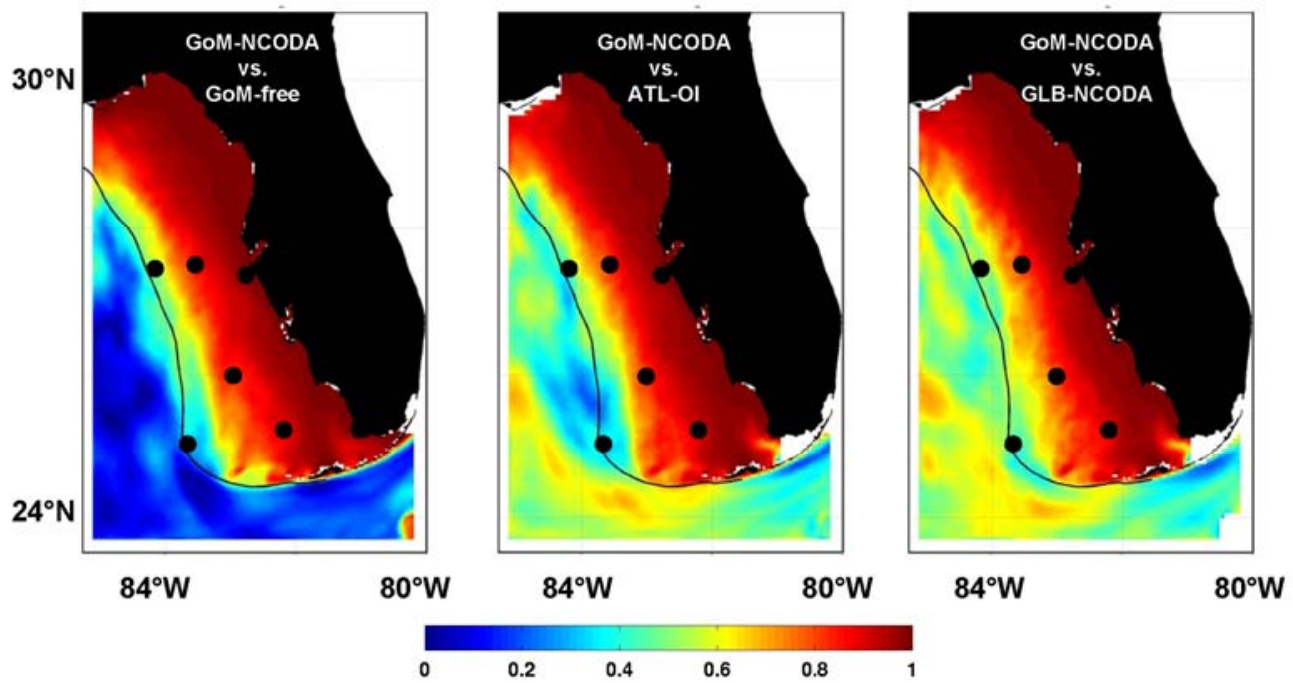

Figure 6. Maps of vector correlation magnitude between 3-hourly surface velocity fields from nested experiment GoM-NCODA and each of the other three experiments: GoM-free (left), ATLOI (center), and GLB-NCODA (right). Locations of the six moorings used in the Taylor diagram analysis (Figure 5) are shown with black dots. The three northern moorings are, from offshore to coast, $\mathrm{C} 16, \mathrm{C} 12$, and $\mathrm{C} 15$. The three southern moorings are, from offshore to coast, $\mathrm{C} 18, \mathrm{C} 13$, and C17. 

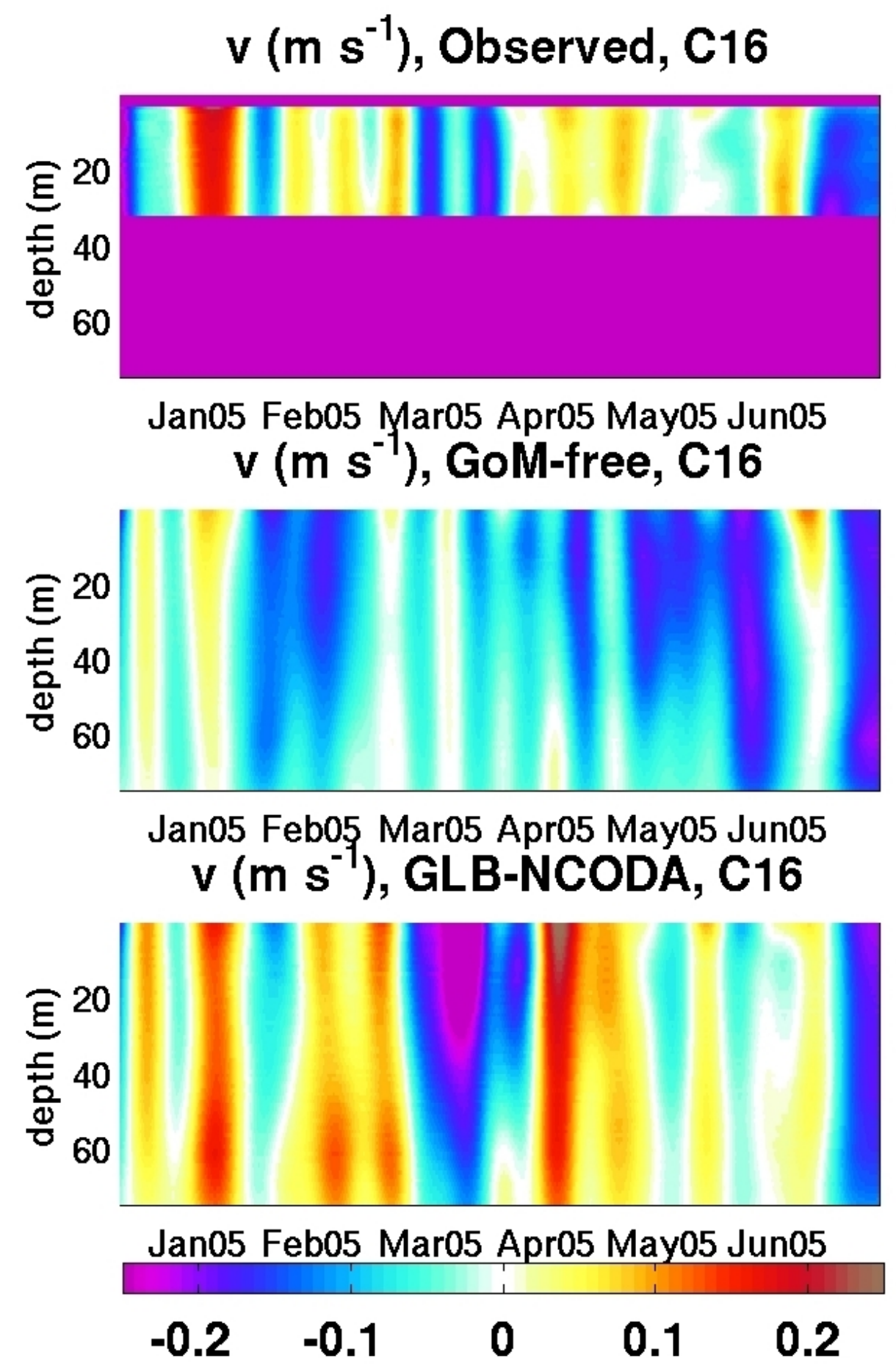

Figure 7. Time-depth plots of the alongshore velocity component during the first six months of 2005 at ADCP mooring C16. 

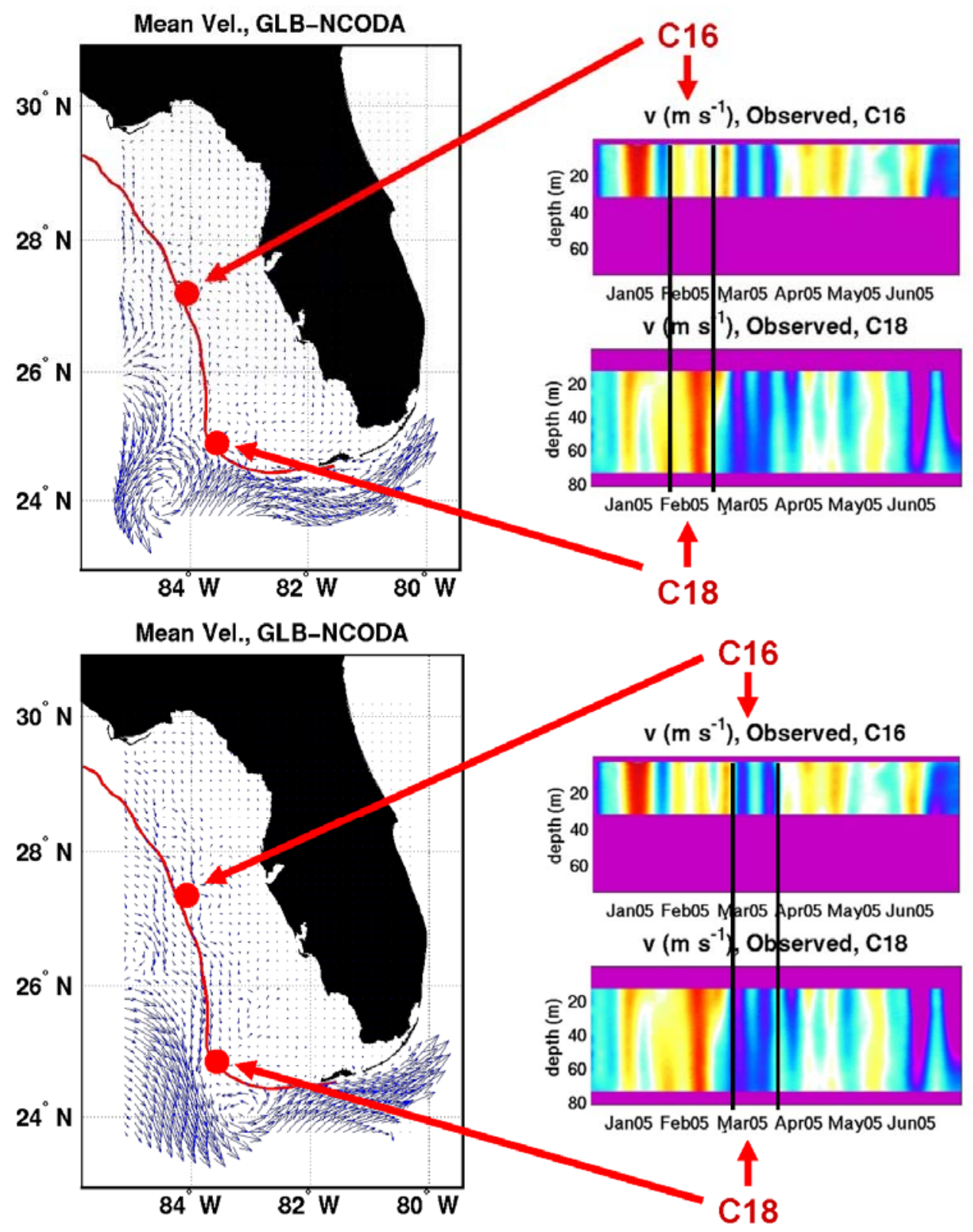

Figure 8. Mean surface velocity maps from experiment GLB-NCODA (upper-left) over 26 January to 14 February 2005 when persistent northward flow was observed over the outer shelf at both moorings $\mathrm{C} 16$ and $\mathrm{C} 18$ (upper right). Mean surface velocity maps from experiment GLB-NCODA over 26 February 2005 to 17 March 2005 (lower left) when southward flow was observed at the same two moorings (lower right). The $100 \mathrm{~m}$ isobath is shown in the velocity maps. 

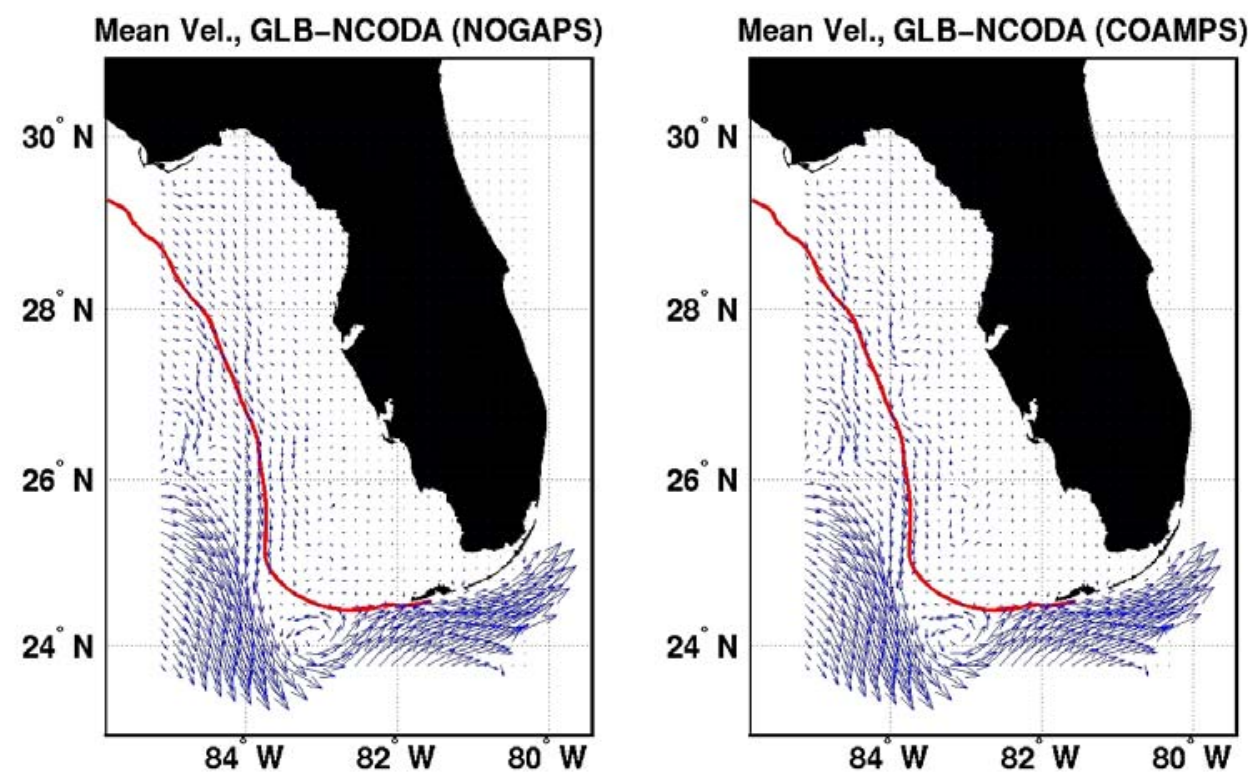

Figure 9. Mean surface velocity fields over the time interval 26 February 2005 through 17 March 2005 from experiment GoM-NCODA (left) and a second GLB-NCODA experiment (right) that was forced by atmospheric fields from the same Navy 0.5-degree NOGAPS atmospheric model that was used to force the GLB-NCODA outer model. The $100 \mathrm{~m}$ isobath is shown. 

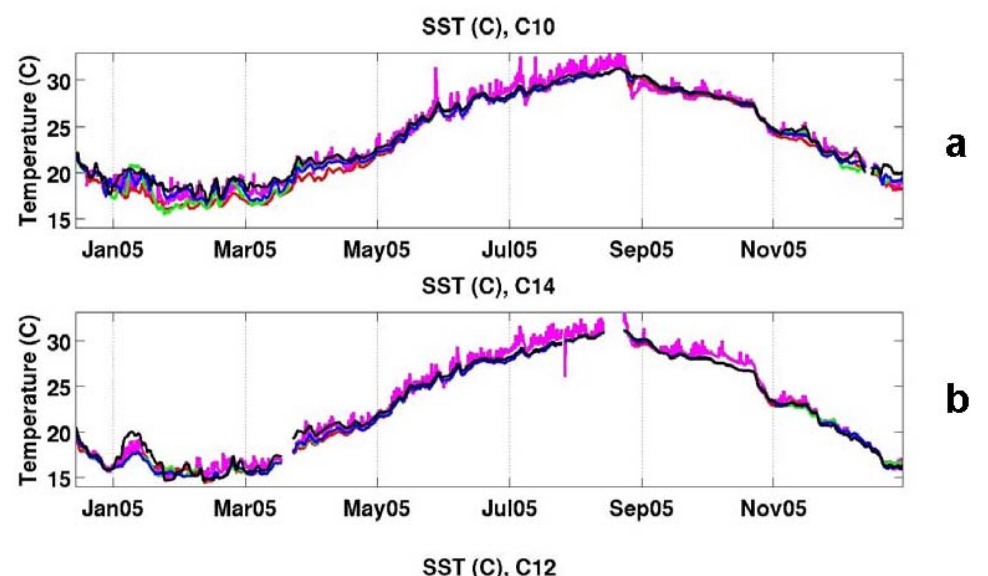

b

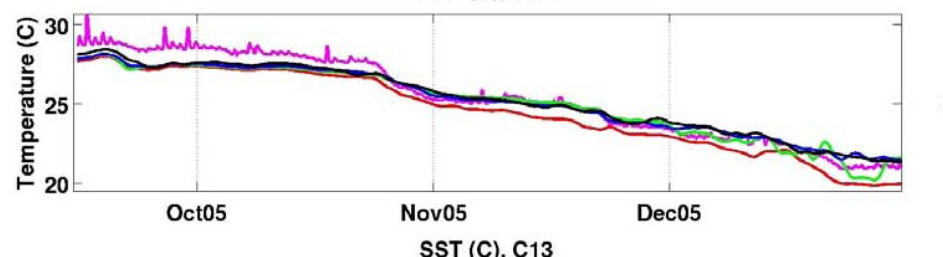

C

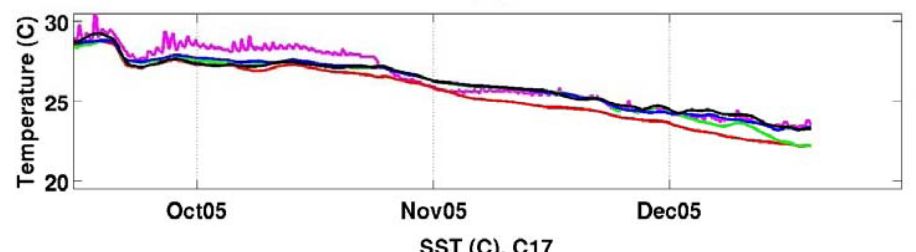

d

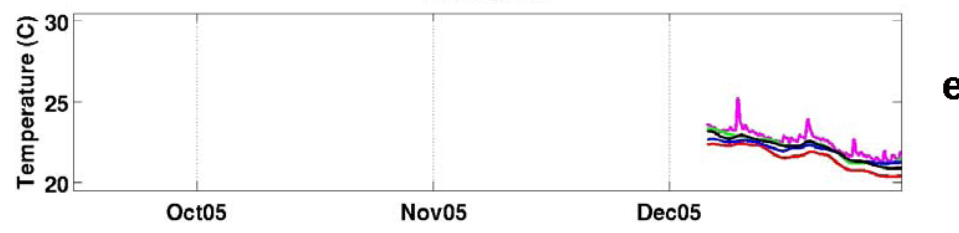

SST (C), C12

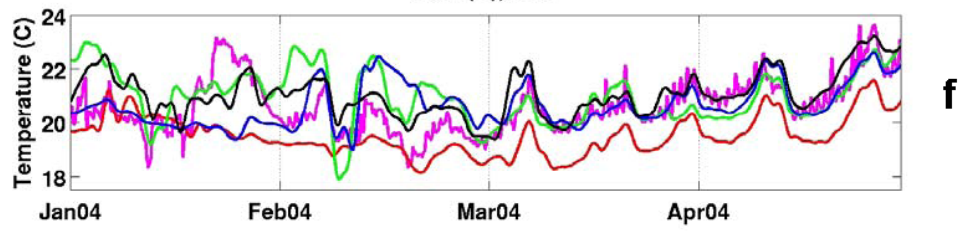

SST (C), C17

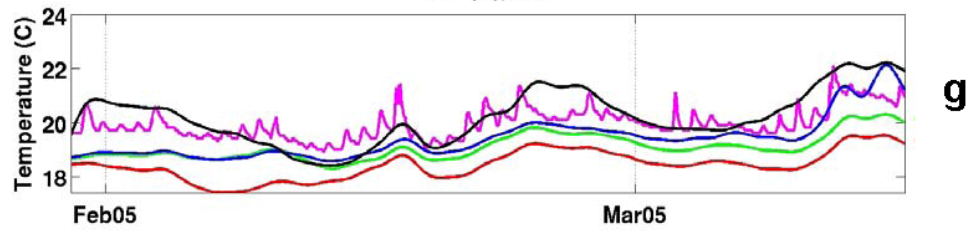

Figure 10. Sea surface temperature time series for selected time intervals measured by surface instrumentation at the COMPS moorings. Panels (a) and (b) are for nearshore moorings $\mathrm{C} 10$ and C14 for mid-December 2004 through 2005. Panels (c), (d), and (e) are for moorings C12, C13, and C17 during fall 2005. Panels (f) and (g) are for two winter/spring intervals, C12 for 2004 and C17 for 2005. Red lines are for experiment GoM-free, green lines for GoM-NCODA, blue lines for ATL-OI, and solid black lines for GLB-NCODA. The magenta lines represent the observations. 
T (C), C12, GoM-NCODA

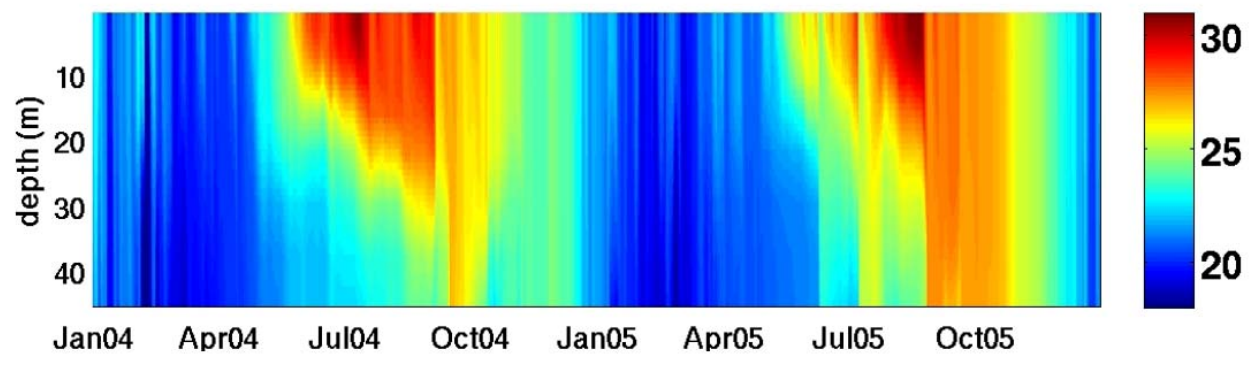

T (C), C12, GoM-free minus GoM-NCODA
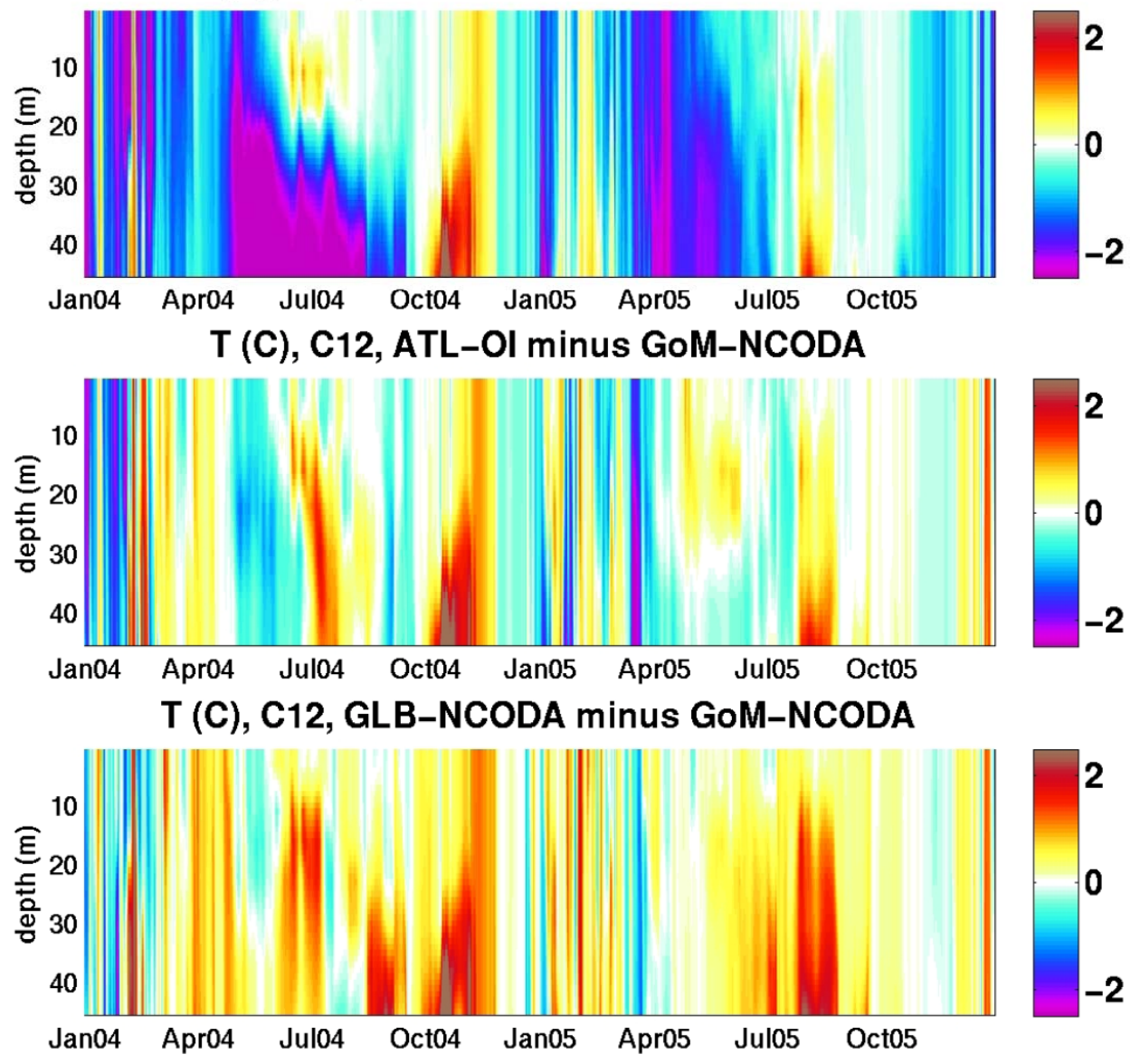

Figure 11. Depth-time plot of temperature at mooring C12 simulated by experiment GoMNCODA (top panel) along with the temperature differences observed between experiments GoMfree, ATL-OI, and GLB-NCODA and experiment GoM-NCODA (bottom 3 panels). 

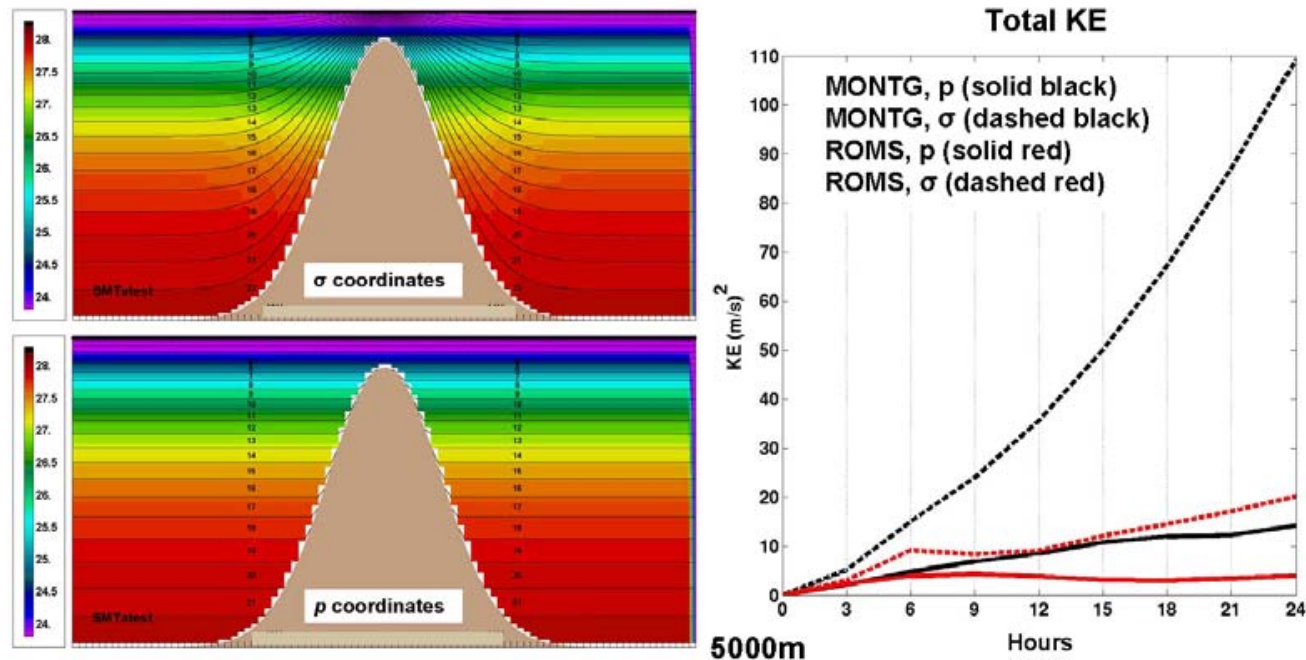

Figure 12. Initial density field and vertical coordinates for the $p$ and $\sigma$ coordinate seamount tests (left). Temporal evolution of kinetic energy over the first day of integration for the four seamount tests. 